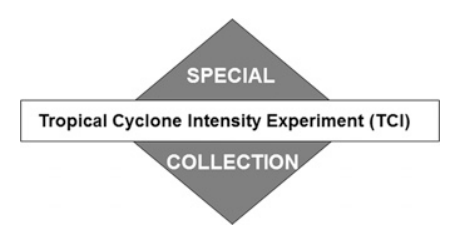

\title{
Impact of Assimilating Upper-Level Dropsonde Observations Collected during the TCI Field Campaign on the Prediction of Intensity and Structure of Hurricane Patricia (2015)
}

\author{
JiE Feng AND Xuguang WANG \\ School of Meteorology, University of Oklahoma, Norman, Oklahoma
}

(Manuscript received 27 August 2018, in final form 5 June 2019)

\begin{abstract}
The dropsondes released during the Tropical Cyclone Intensity (TCI) field campaign provide high-resolution kinematic and thermodynamic measurements of tropical cyclones within the upper-level outflow and inner core. This study investigates the impact of these upper-level TCI dropsondes on analyses and prediction of Hurricane Patricia (2015) during its rapid intensification (RI) phase using an ensemble-variational data assimilation system. In the baseline experiment (BASE), both kinematic and thermodynamic observations of TCI dropsondes at all levels except the upper levels are assimilated. The upper-level wind and thermodynamic observations are assimilated in additional experiments to investigate their respective impacts. Compared to BASE, assimilating TCI upper-level wind observations improves the accuracy of outflow analyses verified against independent atmospheric motion vector (AMV) observations. It also strengthens the tangential and radial wind near the upper-level eyewall. The inertial stability within the upper-level eyewall is enhanced, and the maximum outflow is more aligned toward the inner core. Additionally, the analyses including the upper-level thermodynamic observations produce a warmer and drier core at high levels. Assimilating both upper-level kinematic and thermodynamic observations also improves the RI forecast. Compared to BASE, assimilating the upper-level wind induces more upright and inward-located eyewall convection, resulting in more latent heat release closer to the warm core. This process leads to stronger inner-core warming. Additionally, the initial warmer upper-level inner core produced by assimilating TCI thermodynamic observations also intensifies the convection and latent heat release within the eyewall, thus further contributing to the improved intensity forecasts.
\end{abstract}

\section{Introduction}

In recent decades, research has shown that the tropical cyclone (TC) outflow layer is critically related to the TC structure evolution and intensity change rather than just a mechanism to export TC energy at the upper troposphere. The outflow layer relative to the low- and midtroposphere has weaker inertial stability and thus is more susceptible to the environmental forcing (Holland and Merrill 1984; Rappin et al. 2011). For example, the outflow can interact with a midlatitude trough, producing the inward cyclonic eddy momentum flux (Merrill 1988a; Molinari and Vollaro 1989). The changes in the TC outflow can directly lead to the variation of TC secondary circulation and can therefore influence the storm intensity (Holland and Merrill 1984; Merrill 1988b; Komaromi and Doyle 2017).

Corresponding author: Xuguang Wang, xuguang.wang@ou.edu
In addition to the outflow, changes to the upper-level warm core have some impacts on TC intensity variation. The subsidence of stratospheric air in the center of hurricanes is responsible for adiabatic warming of upper-level warm cores (Zhang and Chen 2012; Chen and Zhang 2013). Moreover, the warming at the upperlevel inner core is consistent with the surface pressure deficit according to diagnosis through the hydrostatic pressure equation (Hirschberg and Fritsch 1993; Holland 1997; Zhang and Chen 2012).

To understand the role of the upper-level portion of the TC on its evolution, observations that sample the TC outflow and upper-level inner core are crucial. The satellite atmospheric motion vector (AMV) is retrieved by tracking cloud and water vapor features and can estimate the upper-tropospheric wind around $150 \mathrm{hPa}$ (Poteat 1973; Franklin et al. 1990; Sears and Velden 2012), covering the major part of the TC environmental outflow. Dropsondes onboard manned 
TABLE 1. Comparisons of different types of dropsonde observations and atmospheric motion vector (AMV); $T, Q, U$, and $V$ denote temperature, specific humidity, and horizontal and meridional winds, respectively. ODW, AVAPS, HDSS, and XDD represent omega dropwindsonde, advanced vertical atmospheric profiling system, high definition sounding system, and expendable digital dropsonde, respectively.

\begin{tabular}{lccccccc}
\hline \hline \multicolumn{1}{c}{ Aircraft } & $\begin{array}{c}\text { Variables } \\
\text { observed }\end{array}$ & Altitude & $\begin{array}{c}\text { Radius of } \\
\text { collected data }\end{array}$ & $\begin{array}{c}\text { Horizontal/profile } \\
\text { resolution }\end{array}$ & Duration & $\begin{array}{c}\text { No. of dropsondes/ } \\
\text { mission }\end{array}$ & Dropsonde \\
\hline G-IV & $T, Q, U, V$ & $\begin{array}{c}<150 \mathrm{hPa} \\
(\sim 13.7 \mathrm{~km})\end{array}$ & $\sim 1000 \mathrm{~km}$ & $150-200 \mathrm{~km} ; 0.5 \mathrm{~s}$ & $8-9 \mathrm{~h}$ & $\sim 30$ & GPS based \\
Global Hawk & $T, Q, U, V$ & $<18.2 \mathrm{~km}$ & $\sim 500 \mathrm{~km}$ & $\mathrm{Up} \mathrm{to} \sim 25 \mathrm{~km}^{\mathrm{a}} ; 0.5 \mathrm{~s}$ & $\sim 30 \mathrm{~h}$ & Up to 90 & AVAPS RD-94 \\
WB-57 & $T, Q, U, V$ & $<18.3 \mathrm{~km}$ & $\sim 300 \mathrm{~km}$ & $\mathrm{Up} \mathrm{to} 4-10 \mathrm{~km}^{\mathrm{b}} ; 0.5 \mathrm{~s}$ & $\sim 6 \mathrm{~h}$ & $\sim 85$ & HDSS and XDD \\
Satellite (AMV) & $U, V$ & $<150 \mathrm{hPa}$ & - & - & - & - & - \\
& & $(\sim 13.7 \mathrm{~km})$ & & & & & \\
\hline
\end{tabular}

${ }^{\text {a }}$ Corresponding to a sonde release frequency of $2.5 \mathrm{~min}$ and a cruising speed of $170 \mathrm{~m} \mathrm{~s}^{-1}$ (Intrieri et al. 2014).

${ }^{\mathrm{b}}$ From the TCI experiment for Hurricane Patricia (Rogers et al. 2017). TCI dropsondes can be released up to 40 over a small time window (Black et al. 2017) relative to only 8 for GH dropsondes (Intrieri et al. 2014).

reconnaissance aircraft such as the NOAA GulfstreamIV (G-IV) gather the profiles of wind direction and speed, temperature, and humidity with the highest altitude at about $150 \mathrm{hPa}(\sim 14 \mathrm{~km})$. The G-IV flies within an approximately $1000-\mathrm{km}$ radius of the TC center (Burpee et al. 1996; Aberson and Franklin 1999), primarily sampling the TC environment. During the recent field campaigns such as the National Aeronautics and Space Administration (NASA) Hurricane and Severe Storm Sentinel (HS3) project (Braun et al. 2016) and National Oceanic and Atmospheric Administration (NOAA) Sensing Hazards with Operational Unmanned Technology (SHOUT) program, an unmanned aircraft system (UAS) named Global Hawk $(\mathrm{GH})$ was used to release dropsondes to collect kinematic and thermodynamic observations in both the inner-core region and the environment at a much higher altitude $(\sim 18 \mathrm{~km})$ than the G-IV aircraft (Hock and Franklin 1999). These GH dropsonde observations can better depict the structure and evolution of the upper-level outflow and warm core compared to the G-IV dropsondes. Detailed comparisons of the above observations are summarized in Table 1.

During the 2015 Office of Naval Research (ONR) Tropical Cyclone Intensity (TCI) field campaign, the NASA aircraft WB-57 was launched and flew at an altitude of nearly $18 \mathrm{~km}$, similar to the GH. Such a highflying altitude allows the dropsondes released to sample the entire depth of the TC up to the lower stratosphere. The flight track was designed to sample both the TC inner-core and near-storm regions (Doyle et al. 2017). The new dropsonde technology in the TCI campaign provides the wind, temperature, and humidity observations with much higher horizontal resolution than the GH (Braun et al. 2016; Black et al. 2017; see Table 1). The TCI dropsondes were released almost five times more frequently than the GH dropsondes (Intrieri et al. 2014; Black et al. 2017). Therefore, the unique fine scales of the near-storm outflow and the inner-core structure were better depicted (Doyle et al. 2017). This fine resolution sampling is particularly valuable when the TC has a relatively small size like Patricia (Rogers et al. 2017).

There are already a number of airborne observing systems with the ability to sample the kinematic and thermodynamic variables of TC at mid- to lower levels, such as the dropsondes, airborne radar, and flight-level instruments on board the traditional G-IV and WP-3D aircraft that take routine reconnaissance flights during the hurricane seasons. The impacts of such data have been investigated extensively (Aberson and Franklin 1999; Zhang et al. 2011; Aksoy et al. 2013; Lu et al. 2017a). However, studies on the impact of assimilating observations sampling TC at upper levels are limited. Majumdar et al. (2013) investigated the impact of assimilating the G-IV dropsonde observations on the track forecast from the perspective of the interaction of the outflow with the large-scale environment. Wu et al. (2015) found that the interior and upper-level $(100-350 \mathrm{hPa})$ AMVs played an important role in improving the forecasts of TC intensity and wind structures. The assimilation of the new AMV data was also found to positively influence the TC track and intensity predictions (Lim et al. 2019).

Compared to the above observations, the TCI dropsondes provide an unprecedented high-resolution sampling of the TC warm core and near-storm outflow at upper levels. However, the value in deploying highflying aircraft such as WB57 to take these additional upper-level observations is still unclear. Therefore, the major goal of the present study is to explore the individual and combined impacts of kinematic and 
thermodynamic observations at upper levels collected by the TCI dropsondes on the analysis and prediction of the TC structure and rapid intensification (RI). Here, we use Hurricane Patricia (2015) as a case study to explore these impacts. Additionally, this study aims to investigate and understand the RI mechanism by diagnosing the observation impacts.

This study adopts an experimental version of the Hurricane Weather Research and Forecasting system (HWRF; Tallapragada et al. 2016). The system used here, developed by Lu et al. (2017a, b), is a continuously cycled, dual-resolution 3D and 4D ensemble-variational (EnVar) data assimilation (DA) system for HWRF. With this DA system, Lu and Wang (2019b, manuscript submitted to Mon. Wea. Rev., hereafter LW19b) compared the impacts of assimilating the TCI dropsonde data at all levels and other observations collected from other field campaigns [e.g., Intensity Forecasting Experiment (IFEX)] on analysis and prediction. They found that assimilating the TCI dropsonde observations better analyzes and predicts the overall three-dimensional structure of Hurricane Patricia. However, the specific impacts of the upper-level observations from the TCI dropsondes, which is the focus of the present study, were not examined in LW19b.

The manuscript is organized as follows. Section 2 gives a brief description of Hurricane Patricia (2015), the preprocessing of the TCI dropsonde data, the model configuration, the DA system, as well as the experimental design. Section 3 shows the intensity forecasts for all experiments. The results and the diagnostics of the impact of TCI dropsondes on TC structure in analyses and subsequent forecasts are shown in sections 4 and 5 , respectively. The conclusions and discussion are presented in the last section.

\section{Data and experiments}

\section{a. Description of the case}

Patricia was an eastern North Pacific TC with a lifetime of just 4.5 days (Kimberlain et al. 2015; Doyle et al. 2017). It was declared a tropical depression at 0600 UTC 20 October 2015 and moved northwestward as the maximum surface $(10 \mathrm{~m})$ winds $(\mathrm{MSW})$ increased to $35 \mathrm{kt}\left(\sim 18 \mathrm{~m} \mathrm{~s}^{-1}\right)$ at 0000 UTC 21 October and $60 \mathrm{kt}$ $\left(\sim 31 \mathrm{~ms}^{-1}\right)$ at 0000 UTC 22 October. Over the next $36 \mathrm{~h}$, Patricia explosively intensified from a tropical storm to a category-5 hurricane, arriving at a remarkable peak with MSW of $185 \mathrm{kt}\left(\sim 95 \mathrm{~m} \mathrm{~s}^{-1}\right)$ and minimum sea level pressure (MSLP) of $872 \mathrm{hPa}$ at 1200 UTC 23 October. The MSW and rate of RI broke historical records for TCs (Rogers et al. 2017; Knapp et al. 2010). During the next $24 \mathrm{~h}$, the storm rapidly weakened due to increased environmental vertical wind shear and its landfall. More details concerning the evolution of Patricia can be found in Rogers et al. (2017).

There were four missions that collected TCI dropsondes for Patricia, but only the third one around 1800 UTC 22 October was during its explosive intensification. We will use this mission to investigate the impact of assimilating TCI upper-level dropsonde observations.

\section{b. TCI dropsonde data and processing}

The TCI field campaign utilized the NASA Johnson Space Center at Ellington Field WB-57 research aircraft, which has a cruising altitude of approximately $18 \mathrm{~km}$, such that it flies above the outflow layer of a TC (Doyle et al. 2017). The TCI dropsondes can thus be deployed to sample the whole depth of the TC from the top of the outflow to the ocean surface in the TC nearstorm environment and particularly the inner-core region. The new High-Definition Sounding System (HDSS) and expendable digital dropsonde technology (XDD; Black et al. 2017) provide a unique capability to sample the $\mathrm{TC}$ with much higher horizontal resolution than the $\mathrm{GH}$ and traditional dropsondes (see Table 1). The measurements of TCI dropsondes include global positioning system (GPS)-based location, altitude, horizontal wind, temperature, and humidity. The horizontal distribution of observations (see Figs. 4a,b) shows that the aircraft in the TCI mission flew across the hurricane center and collected observations in the inner core and eyewall with particularly high resolution.

The raw TCI dropsonde data have first gone through quality control (QC) by the TCI investigators, detailed in Bell et al. (2016). Two additional preprocessing steps were performed before the assimilation in this study. Due to the dense sampling, the model resolution as configured in the current study may not resolve the fine spatial and temporal structure captured by the TCI dropsondes. Therefore, the TCI dropsonde observations are superobbed to improve the data assimilation (DA) efficiency and performance (Alpert and Kumar 2007; LW19b). Observations within a defined spatial grid box $\Delta x \times \Delta y \times \Delta z$ and for a certain time interval $\Delta t$ are averaged to construct a single observation, the so-called super-obbing. Tests performed by the authors and LW19b show that the superobbing prism with approximately two times the model grid spacing produces the best TC intensity forecast. Specifically, $\Delta x$ and $\Delta y$ are $0.04^{\circ}(\sim 4 \mathrm{~km}), \Delta z$ nearly spans two model layers (at an interval of about 10,50 , and $20 \mathrm{hPa}$ at lower, middle, and upper levels, respectively), and $\Delta t$ is $15 \mathrm{~min}$. An additional QC procedure is performed within the Gridpoint Statistical Interpolation (GSI) DA system 
(Hu et al. 2018). The major step is the gross error check using the following ratio:

$$
\text { ratio }=(O-B) / \max \left[\text { ermin, } \min \left(\operatorname{ermax}, e_{\mathrm{obs}}\right)\right],
$$

where $O, e_{\mathrm{obs}}$, and $B$ represent the assimilated observation, observational error, and background forecast, respectively; ermin and ermax are the given minimum and maximum error parameters in the convinfo file of GSI. If ratio is larger than an adjustable threshold gross, then the observation fails the gross error check and will be rejected. Figure 1 shows the number of available (black) and actually assimilated (red; i.e., those that have passed the DA QC checks) observations after the raw data QC and the superobbing for individual variables at each level collected during the mission around 1800 UTC 22 October 2015. It can be seen that lowquality data, especially the specific humidity $(Q)$ observations above $200 \mathrm{hPa}$ and below $500 \mathrm{hPa}$, have been excluded through the raw data QC. The observations for variables zonal $(U)$ and meridional $(V)$ winds and temperature $(T)$ cover all levels from about $100 \mathrm{hPa}$ down to the sea surface. The $Q$ observations cover from $200 \mathrm{hPa}$ down to the sea surface. The observations of $T$ and $Q$ passed the GSI QC throughout all levels. About 10\%$20 \%$ of wind observations above $400 \mathrm{hPa}$ were rejected during the GSI QC.

\section{c. HWRF Model configuration}

The HWRF Model configuration during the DA cycling follows the 2015 operational configuration (Zhang et al. 2016). Operational HWRF is triply nested with $18 / 6$ / $2-\mathrm{km}\left(0.135^{\circ} / 0.045^{\circ} / 0.015^{\circ}\right)$ horizontal resolution and has 61 vertical levels with a model top at $2 \mathrm{hPa}$. The outermost, intermediate, and innermost domains are configured with $288 \times 576,304 \times 604$, and $265 \times 472$ horizontal grid points (approximately $80^{\circ} \times 80^{\circ}, 27^{\circ} \times 27^{\circ}$ and $7^{\circ} \times 7^{\circ}$ in size, respectively). The HWRF Model physics include the following: 1) the simplified Arakawa-Schubert (SAS) cumulus parameterization scheme (Han and Pan 2006), and the Ferrier-Aligo microphysics scheme (Ferrier 1994, 2005), 2) the modified surface layer (Kwon et al. 2010) and nonlocal planetary boundary layer (Hong and Pan 1996) parameterization schemes, and 3) the Eta Geophysical Fluid Dynamics Laboratory (GFDL) longwave and shortwave radiation schemes (Schwarzkopf and Fels 1991; Lacis and Hansen 1974). Note that the SAS cumulus scheme is only implemented for the outer two domains (i.e., 18- and 6-km grids), but not for the innermost domain with $2-\mathrm{km}$ horizontal resolution in both DA cycling and free forecasts.

For Patricia, neither dynamic nor statistical models were able to provide a forecast of MSW above $100 \mathrm{kt}\left[\sim 51 \mathrm{~m} \mathrm{~s}^{-1}\right.$;

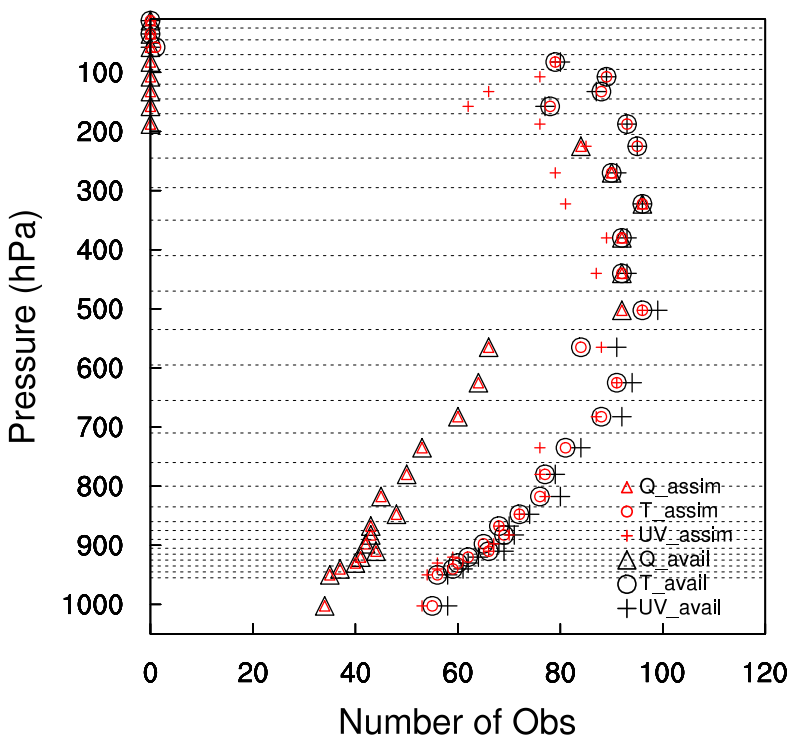

FIG. 1. The number of superobbed observations of zonal $(U)$ and meridional $(V)$ winds, temperature $(T)$, and specific humidity $(Q)$ from the TCI dropsondes at each level (labeled by dashed lines) collected during the mission around 1800 UTC 22 Oct. Black and red markers denote the number of available and actually assimilated observations, respectively.

see Fig. 1 in Rogers et al. (2017)]. Lu and Wang (2019a) found that using a new turbulent layer scheme (Zhu et al. 2018). combined with increasing the horizontal grid resolution strengthened the predicted RI rate and increased the peak intensity. The former replaces the boundary layer top with a "turbulent layer" top and modifies the turbulent mixing parameterization. Specifically, the discontinuity of the vertical diffusivity in deep convection is eliminated (see more in Zhu et al. 2018 and Lu and Wang 2019a). The higher model resolution better resolves the TC finescale structures, which is especially important for a small hurricane like Patricia. In this study, to make the baseline experiment as accurate as possible, differing from the operational configuration, the HWRF Model during the free forecast is configured with a higher horizontal resolution of $9 / 3 / 1-\mathrm{km}$ grid spacing $\left(0.09^{\circ} / 0.03^{\circ} / 0.01^{\circ}\right)$ over a reduced domain size $\left(55^{\circ} \times 55^{\circ}, 18^{\circ} \times 18^{\circ}\right.$ and $\left.6^{\circ} \times 6^{\circ}\right)$. Following LW19b, in addition to using the new "turbulence layer" scheme (Zhu et al. 2018; Zhang et al. 2018), we reduced the horizontal diffusion "coac" parameter from 0.75/3.0/4.0 to $0.75 / 1.0 / 1.2$ for the $9 / 3 / 1-\mathrm{km}$ domains as well.

\section{d. Data assimilation system}

The experiments are conducted using the GSI-based EnVar data assimilation for HWRF with continuous cycling and a dual-resolution configuration ( $\mathrm{Lu}$ et al. 2017a, b), extended from the GSI EnVar hybrid DA 
system for the global prediction system (e.g., Wang et al. 2013; Wang and Lei 2014). The initial conditions in the outer domain with an $18-\mathrm{km}$ grid are directly interpolated from the global analysis of the operational Global Forecast System (GFS) hybrid DA system at National Centers for Environmental Prediction (NCEP; Wang et al. 2013). As for the two inner domains on the 6- and 2 -km grids, the background fields use the 3-hourly control forecasts valid at 3,6 , and $9 \mathrm{~h}$ initialized from the previous DA cycle. The ensemble-based error covariance is calculated from 40 6-hourly recentered ensemble forecasts initiated from the HWRF ensemble Kalman filter (EnKF) analyses from the previous DA cycle (i.e., continuous cycling). The control analysis is updated using the EnVar scheme (Wang 2010). Note that the dual-resolution DA capability is implemented so that only the ensemble covariance at the intermediate domain on the $6-\mathrm{km}$ grid is estimated and applied to the DA at both inner 6- and 2-km domains for computational efficiency. More details of the EnVar scheme and the continuously cycled DA system for HWRF can be found in Lu et al. (2017a, b).

In our experiments, for both the 2- and 6-km control analyses the full ensemble covariance without combining the static covariance is used since past studies show no improvement from using the default static covariance (Schwartz 2016 and Lu et al. 2017b). Following Lu et al. (2017a, b), the posterior ensemble variance is inflated using a factor of 0.9 to prevent possible filter divergence during the DA. The ensemble covariance is spatially localized with horizontal and vertical $e$-folding distances of $150 / 180 \mathrm{~km}$ and $-0.46 /-0.46$ scale height, respectively for the innermost and intermediate domains and no localization is applied to cross-variable covariance.

\section{e. Experiment design}

The TCI dropsonde data are assimilated at intermediate and inner domains (6- and 2- $\mathrm{km}$ grid spacing) at 1800 UTC 22 October 2015 with a 6-h time window centered on the analysis time. In the baseline experiment ("BASE"), the TCI dropsondes below $250 \mathrm{hPa}$ (approximately at the bottom of outflow) are the only observations assimilated. As discussed in section 1, this experiment is designed to mimic the dropsondes released from the lower flying aircraft. To evaluate the individual impact of the kinematic and thermodynamic observations in upper levels, additional experiments are conducted assimilating $T$ and $Q$ ("HLTCITQ") or $U$ and $V$ ("HLTCIUV") above $250 \mathrm{hPa}$ relative to BASE. The experiment "HLTCIQ" is also carried out to reveal the impact of upper-level $Q$ observations. The fifth experiment assimilates all variables throughout all levels ("ALLTCI"). The descriptions of the experiments are
TABLE 2. Descriptions of the experiments.

\begin{tabular}{lc}
\hline \hline Experiment & \multicolumn{1}{c}{ Description } \\
\hline BASE & $\begin{array}{c}\text { Only assimilate the TCI dropsonde data } \\
\text { below } 250 \mathrm{hPa} \\
\text { HLTCIUV }\end{array}$ \\
& $\begin{array}{c}\text { Same as "BASE", but additionally } \\
\text { assimilate TCI UV dropsonde } \\
\text { observations above } 250 \mathrm{hPa} \\
\text { HLTCITQ }\end{array}$ \\
Same as "BASE", but additionally \\
assimilate TCI TQ dropsonde \\
observations above $250 \mathrm{hPa}$ \\
HLTCIQ & $\begin{array}{c}\text { ame as "BASE", but additionally } \\
\text { observations above } 250 \mathrm{hPa}\end{array}$ \\
ALLTCI & Same as "BASE", but additionally \\
& assimilate all TCI dropsonde \\
& observations above $250 \mathrm{hPa}$ \\
\hline
\end{tabular}

given in Table 2. HLTCIUV, HLTCITQ, HLTCIQ, and ALLTCI are designed to investigate if there is any additional value of deploying high flying aircraft such as WB57 to observe the TC inner-core and near-eyewall regions at higher levels on the analysis and prediction of Patricia.

There are other available observations at the analysis time (1800 UTC 22 October) to sample the wind field above $250 \mathrm{hPa}$ of Patricia, such as the TDR (Tail Doppler Radar) and AMV data. Additional experiments were performed to examine the impact of the upper-level TCI dropsonde observations when these additional data were assimilated. It was found that the impact on the analyses and intensity forecasts remains qualitatively similar overall (not shown), suggesting the dominant role of the TCI dropsondes in the upper-level analyses compared to the TDR and AMV observations (LW19b). Therefore, for brevity and simplicity, in the current study, the impact of the upper-level TCI dropsondes is presented without assimilating those additional observations.

The background forecast is initialized from the analysis in the previous DA cycle, which assimilates all conventional in situ data in the "prepbufr" file, SLP in "tcvital", AMVs and satellite radiances (i.e., the "OperH" experiment in LW19b). Before the assimilation of the TCI dropsondes at the 1800 UTC 22 October 2015 cycle, the background is adjusted by using only the vortex relocation but not vortex modification (VM). The results in Lu and Wang (2019a) show that VM causes a spuriously strong and spuriously large primary circulation in the background (see Fig. 3i in Lu and Wang 2019a) despite producing a value of MSW that is consistent with the best track.

As described in section $2 \mathrm{c}$, the analysis assimilating the TCI dropsondes is produced on the $18 / 6 / 2-\mathrm{km}$ grids, whereas the forecast is produced on the $9 / 3 / 1-\mathrm{km}$ grids. 

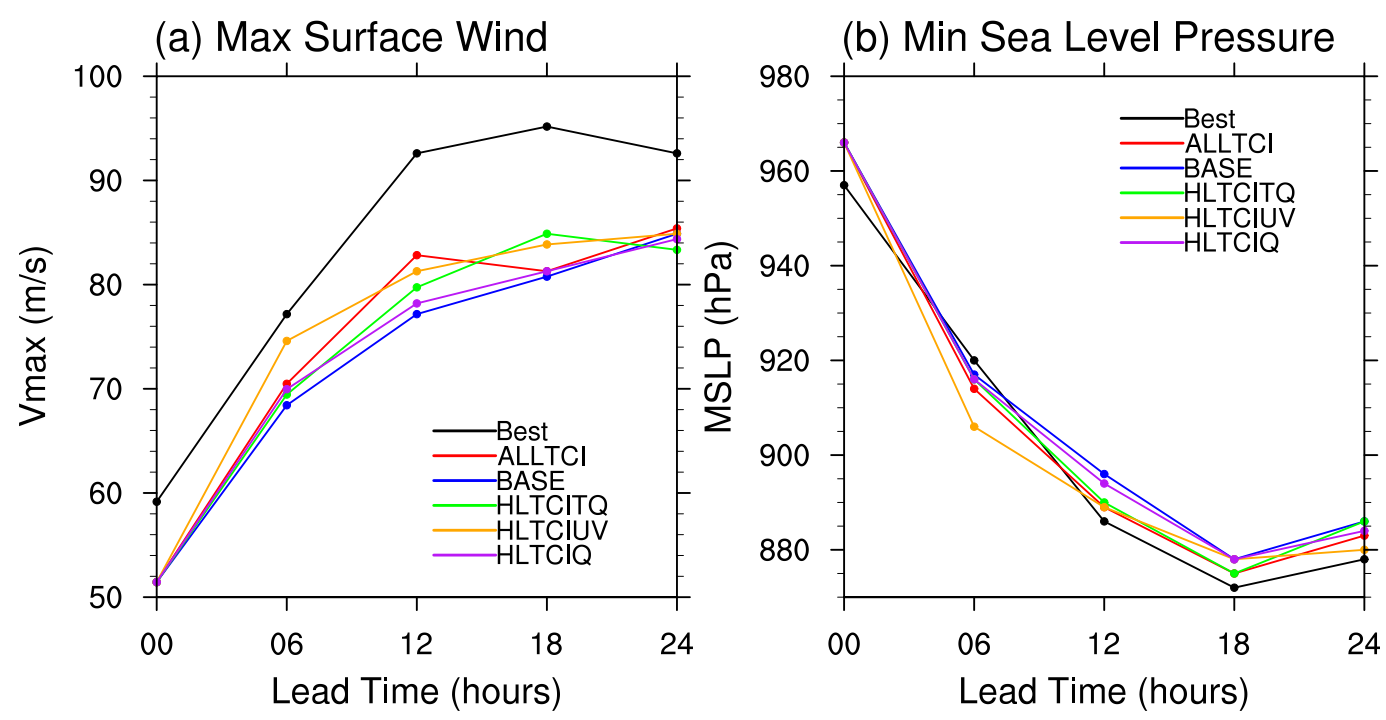

FIG. 2. Forecasts of the (a) maximum surface wind $\left(\mathrm{m} \mathrm{s}^{-1}\right)$ and (b) minimum sea level pressure (hPa) as a function of lead time for the experiments BASE (blue), HLTCITQ (green), HLTCIQ (purple), HLTCIUV (orange), and ALLTCI (red). Black represents the best track.

The initial conditions for the forecasts (i.e., on 9/3/1-km grids) are directly interpolated from the analyses produced on the $18 / 6 / 2-\mathrm{km}$ grids using the interpolation module in the HWRF vortex relocation package (Biswas et al. 2017). The high-resolution free forecasts are carried out for $42 \mathrm{~h}$ at a 6 -h output interval.

\section{Forecast of hurricane intensity}

The track forecasts of the experiments have similar performance (not shown) probably due to the small number of TCI dropsonde observations sampling the large-scale environment. The intensity forecasts of the experiments are shown in Fig. 2 as well as the best track estimates from the National Hurricane Center (NHC). The prediction of the peak intensity is enhanced from approximately MSW $75 \mathrm{~m} \mathrm{~s}^{-1}$ and MSLP $900 \mathrm{hPa}$ with an $18 / 6 / 2-\mathrm{km}$ resolution (not shown) to about $85 \mathrm{~m} \mathrm{~s}^{-1}$ and $880 \mathrm{hPa}$, respectively, due to the increase of resolution to $9 / 3 / 1 \mathrm{~km}$ during model free forecasts. Figure 2 suggests that the differences between the initial analyses at upper levels in all designed experiments impact the RI rate especially during the first $18 \mathrm{~h}$. The intensity and intensification rate for all the experiments are quantified in Table 3. HLTCIUV and HLTCITQ perform the best in the forecasts of intensity and intensification rate at $6 \mathrm{~h}$, respectively, followed by ALLTCI. BASE has the slowest intensification. HLTCIUV has the fastest RI rate in the first $6 \mathrm{~h}$ but overpredicts the RI rate relative to the best track. ALLTCI has the best performance in both evaluations at $12 \mathrm{~h}$. These results suggest that the intensity forecast could benefit from the assimilation of upper-level kinematic and thermodynamic observations. HLTCIQ only slightly improves upon BASE throughout the 18-h lead time probably due to the limited $Q$ observations at upper levels (only up to $200 \mathrm{hPa}$; see Fig. 1). Therefore, the impact of upper-level $Q$ observations will not be independently diagnosed in HLTCIQ. Instead the impact of $Q$ and $T$ observations is jointly diagnosed in HLTCITQ in the following results. The relative performance of the experiments in predicting the MSLP is consistent with the MSW.

To examine the representativeness of the relative performance of MSW, we further compared the time evolution of the maximum azimuthally average of the total wind speed (MAAW) at all levels (Fig. 3).

TABLE 3. Intensity and intensification rate at 6 and $12 \mathrm{~h}$ for BASE, HLTCITQ, HLTCIUV, HLTCIQ, and ALLTCI calculated based on Fig. 2. The best track estimation is given as a reference. The numbers in bold denote the best performance among all experiments.

\begin{tabular}{|c|c|c|c|c|c|c|c|}
\hline & & Best & BASE & ALLTCI & HLTCIUV & HLTCITQ & HLTCIQ \\
\hline \multirow[t]{2}{*}{$6 \mathrm{~h}$} & Intensity $\left(\mathrm{m} \mathrm{s}^{-1}\right)$ & 77.17 & 68.42 & 70.48 & 74.59 & 69.45 & 69.96 \\
\hline & Rate $\left[\mathrm{m} \mathrm{s}^{-1}(6 \mathrm{~h})^{-1}\right]$ & 18.01 & 16.98 & 19.03 & 23.15 & 18.00 & 18.52 \\
\hline \multirow[t]{2}{*}{$12 \mathrm{~h}$} & Intensity $\left(\mathrm{m} \mathrm{s}^{-1}\right)$ & 92.60 & 77.17 & 82.83 & 81.28 & 79.74 & 78.20 \\
\hline & Rate $\left[\mathrm{ms}^{-1}(6 \mathrm{~h})^{-1}\right]$ & 15.43 & 8.75 & 12.35 & 6.69 & 10.29 & 8.20 \\
\hline
\end{tabular}




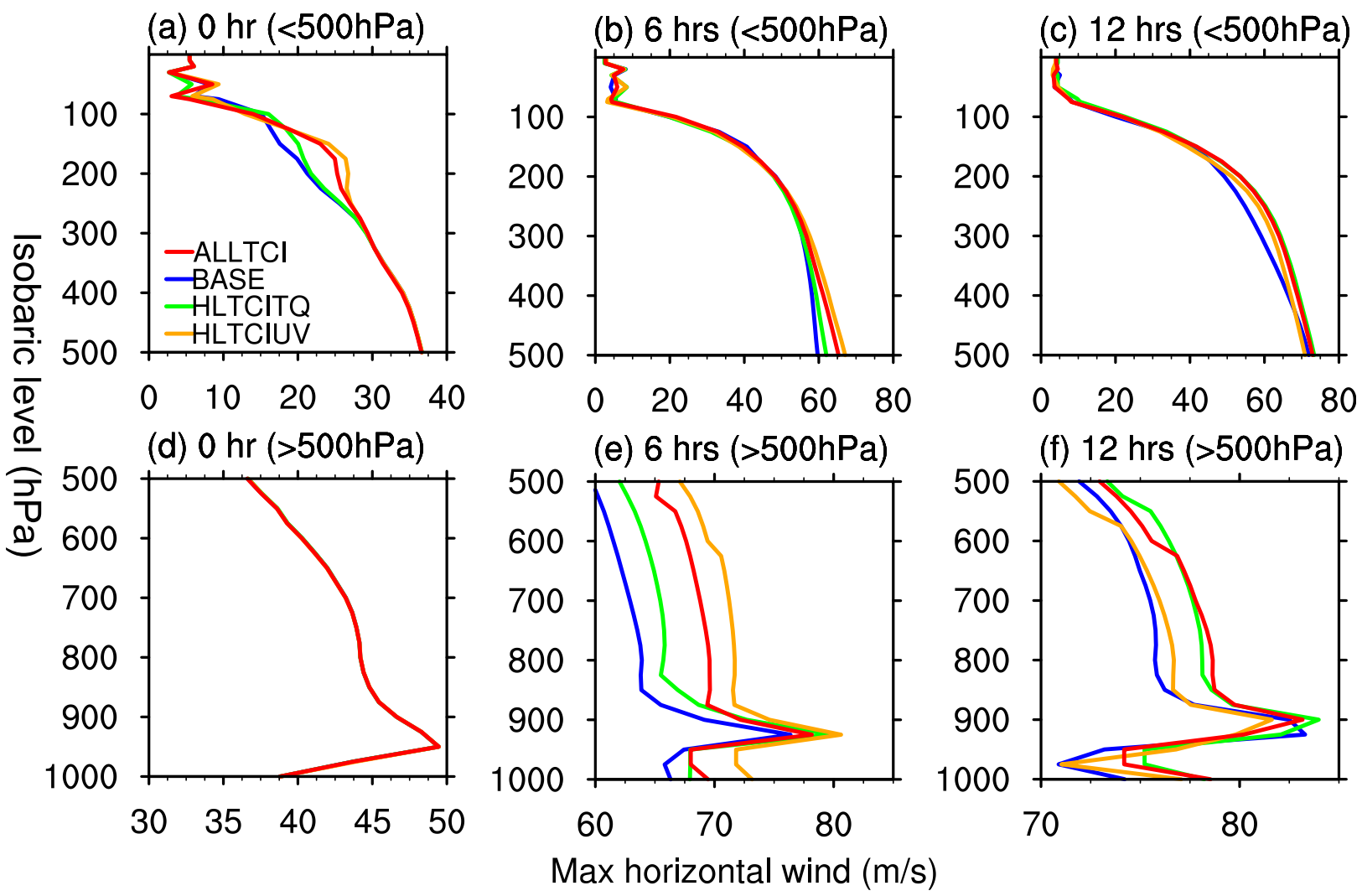

FIG. 3. Time evolution of the maximum azimuthally averaged wind speed at levels (a)-(c) above and (d)-(f) below $500 \mathrm{hPa}$ for the experiments BASE (blue), HLTCITQ (green), HLTCIUV (orange), and ALLTCI (red).

Assimilating the kinematic observations at upper levels (HLTCIUV and ALLTCI) overall strengthens the MAAW in the outflow layer $(\sim 200 \mathrm{hPa})$ at initial time (see Fig. 3a). Such changes result in stronger MAAW throughout the mid- to lower levels (below about $400 \mathrm{hPa}$ ) in HLTCIUV at $6 \mathrm{~h}$ and in ALLTCI at both 6 and $12 \mathrm{~h}$ than in BASE. The assimilation of only the upper-level thermodynamic observations in HLTCITQ also corresponds to stronger MAAW from $500 \mathrm{hPa}$ to the surface at 6 and $12 \mathrm{~h}$, although it is weaker than in HLTCIUV and ALLTCI at $6 \mathrm{~h}$. The results for the MAAW evolution and the prediction of MSW (Fig. 2a) both indicate that assimilating either kinematic or thermodynamic observations from upper-level TCI dropsondes intensifies the eyewall wind.

\section{Impact of TCI upper-level dropsonde observations on TC analyses}

\section{a. Analyses of kinematic variables}

To better understand the differences among intensity forecasts from each experiment in section 3, we first examine how assimilating upper-level TCI dropsonde observations affects analyses of Patricia's kinematic structure. Figures $4 \mathrm{a}-\mathrm{c}$ shows the initial analyses of the wind field at $150 \mathrm{hPa}$ in BASE and ALLTCI and their differences. The 150-hPa level is chosen because it encompasses both the maximum impacts on the outflow and the peak number of verifying AMV observations at 1800 UTC 22 October. The analyses of the experiments HLTCITQ and HLTCIUV are not shown since the former is similar to BASE, while the latter is similar to ALLTCI. The wind fields have apparent differences due to assimilating the upper-level TCI wind observations (cf. Figs. 4a,b), associated with the areas covered by dropsondes (see white dots). ALLTCI overall exhibits stronger wind in the narrow eyewall at a distance of about $30 \mathrm{~km}$ from the hurricane center, but its winds are weaker in the northwestern and southwestern nearstorm outflow environment relative to BASE (Fig. 4c). This result can also be seen in the azimuthally averaged plot (Fig. 6).

The AMV field is used as the independent reference for verifying the analyses of BASE and ALLTCI (Figs. 4d-f). The AMV observations are mostly distributed in the outer environment, providing limited 
(a) Wind BASE @150hPa

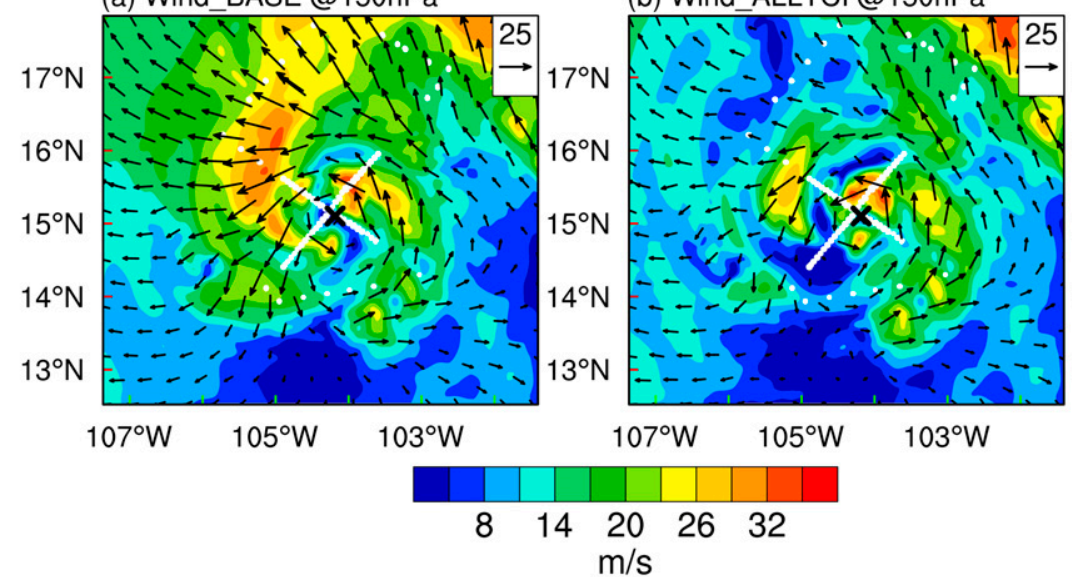

(d) AMV @150hPa (b) Wind_ALLTCI@150hPa

(e) BASE-AMV @150hPa

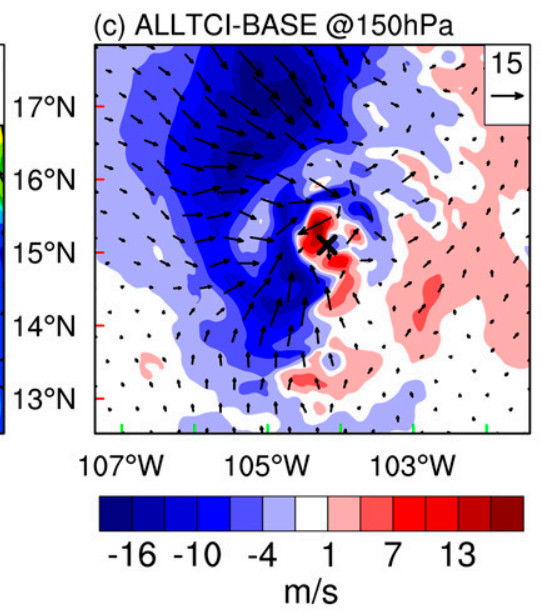

(f) ALLTCI-AMV @150hPa

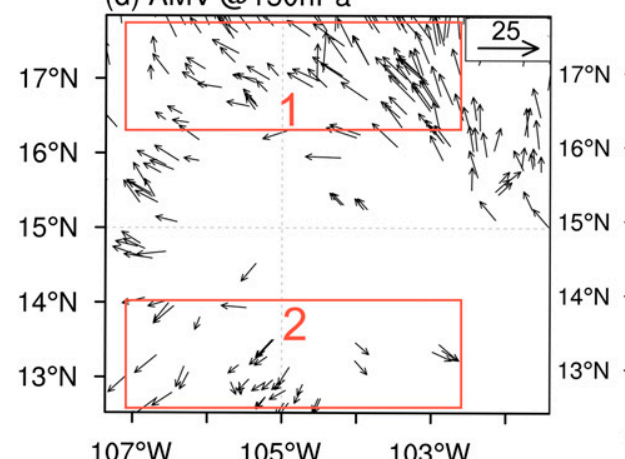

$107^{\circ} \mathrm{W} \quad 105^{\circ} \mathrm{W} \quad 103^{\circ} \mathrm{W}$

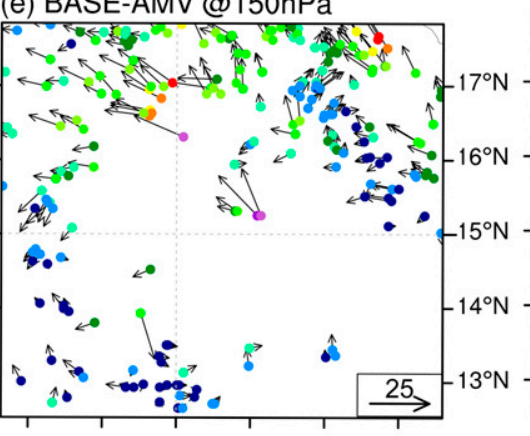

$107^{\circ} \mathrm{W} \quad 105^{\circ} \mathrm{W}$

$103^{\circ} \mathrm{W}$

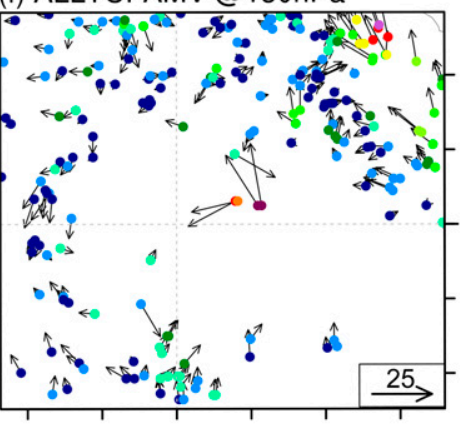

$24 \quad 6 \quad 8 \quad 10 \quad 121416 \quad 18 \quad 202224$

$\mathrm{m} / \mathrm{s}$

FIG. 4. Initial analyses of wind vector (arrow) and magnitude ( $\mathrm{m} \mathrm{s}^{-1}$; shaded) at $150 \mathrm{hPa}$ in the experiments (a) BASE and (b) ALLTCI, and (c) their differences. (d) AMV observations between 140 and $160 \mathrm{hPa}$, and (e),(f) direction (arrow) and absolute magnitude (m s ${ }^{-1}$; dot) errors of wind fields in BASE and ALLTCI verified against AMV, respectively.

value for verifying the analyses near the eyewall. Still, the upper-level wind amplitude in the analysis of ALLTCI has better root-mean-square (RMS) fit to AMV observations $\left(6.26 \mathrm{~m} \mathrm{~s}^{-1}\right)$ than BASE $\left(8.14 \mathrm{~m} \mathrm{~s}^{-1}\right)$.

We further verified the wind amplitude and direction for BASE and ALLTCI in different selected areas (red boxes in Fig. 4d) against AMVs (Fig. 5). In box 1 (Figs. 5a-d) where many TCI dropsonde observations are located (e.g., on the northwestern and northeastern sides of Patricia), ALLTCI has much smaller $\left(4.25 \mathrm{~m} \mathrm{~s}^{-1}\right)$ RMS error of wind magnitude than BASE $\left(9.54 \mathrm{~m} \mathrm{~s}^{-1}\right)$ but similar RMS error of wind direction $\left(25.4^{\circ}\right.$ vs $\left.20.2^{\circ}\right)$. The difference of their wind amplitude errors is significant since it is larger than the uncertainty of AMV observations near $150 \mathrm{hPa}$, which is about 3.5-5 $\mathrm{m} \mathrm{s}^{-1}$ (Velden and Bedka 2009; Cordoba et al. 2017). In contrast, the RMS errors of wind amplitude and direction for BASE and ALLTCI in box 2 (Figs. 5e-h) have no statistically significant differences due to the lack of TCI dropsonde observations. This verification implies a positive impact of assimilating TCI dropsondes on the analysis of the upper-level circulation.

To illustrate the vertical structure of wind components, Fig. 6 shows the azimuthally averaged tangential and radial wind from the analyses. In the BASE experiment (Fig. 6a), the evident eyewall with a maximum tangential wind of about $45 \mathrm{~m} \mathrm{~s}^{-1}$ exists at about $30 \mathrm{~km}$ away from the hurricane center. The radius of the maximum wind (RMW) slopes outward with an increasing altitude, especially above $200 \mathrm{hPa}$ due to the small radial gradient of tangential wind and the maximum of radial wind beyond $80 \mathrm{~km}$. When the upperlevel wind observations are assimilated, both the tangential and radial wind tend to strengthen near the eyewall, and weaken in the outer storm region (see Figs. 6f,g). The radial gradient of tangential wind is thus increased and the maximum of outflow is adjusted inward to about $60 \mathrm{~km}$ (see Figs. 6c,d). Correspondingly, 


\section{Box 1}

(a) Amplitude (BASE)

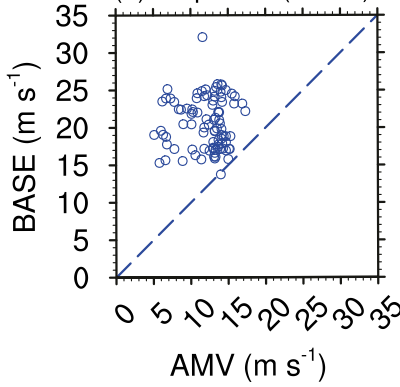

(b) Amplitude (ALLTCI)

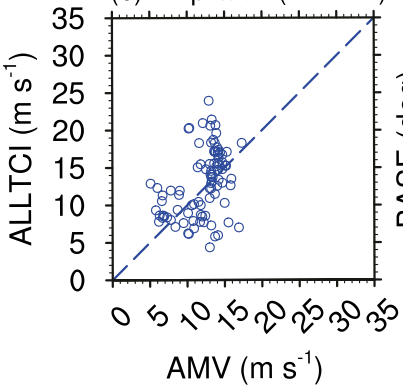

(c) Direction (BASE)

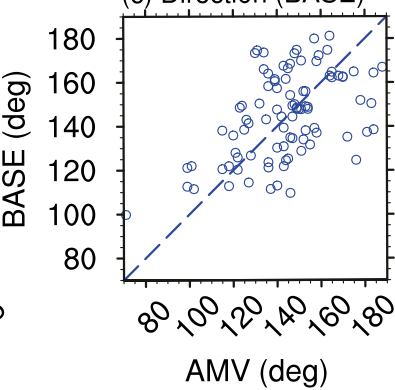

(d) Direction (ALLTCI)

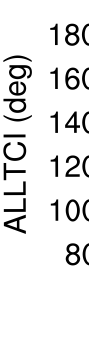

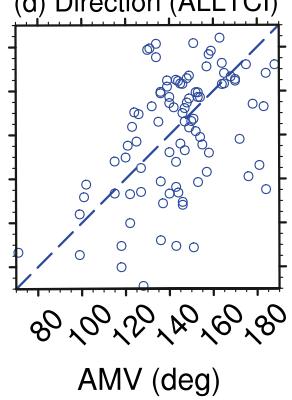

\section{Box 2}

(e) Amplitude (BASE)

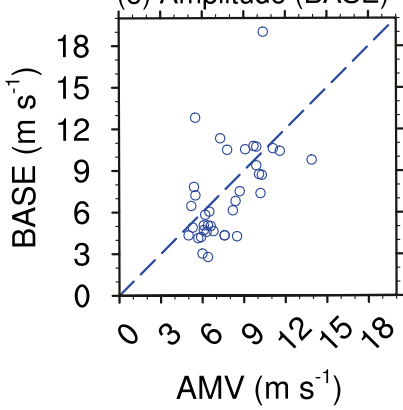

(f) Amplitude (ALLTCI)

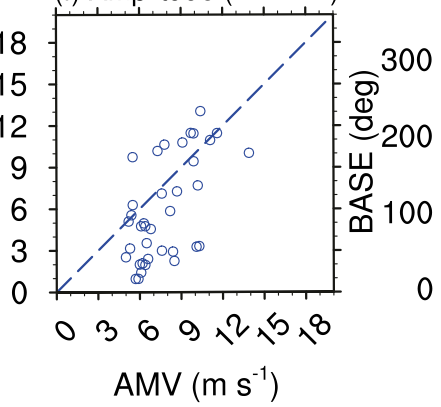

(g) Direction (BASE)

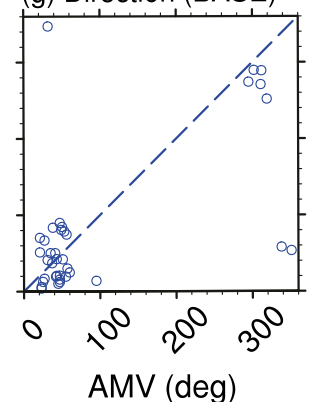

FIG. 5. Scatterplots of wind amplitude for AMVs and analyses of (a) BASE and (b) ALLTCI in box 1 highlighted in Fig. 4d. (c),(d) As in (a),(b), but for wind direction. (e)-(h) As in (a)-(d), but for box 2.

the RMW exhibits much less tilt and extends vertically to a higher level in HLTCIUV and ALLTCI. Although the outflow peak level stays the same at $100 \mathrm{hPa}$ for all experiments, the depth of the outflow layer in HLTCIUV and ALLTCI becomes thinner as the result of assimilating the upper-level wind observations from the TCI dropsondes (cf. Figs. 6c,d and a,b). This result is consistent with the fact that the maximum reduction of outflow is at $150 \mathrm{hPa}$, below the peak level (Figs. 6f,g). It is noteworthy that the assimilation of $T$ and $Q$ observations, through the crossvariable covariance, has only a small impact on the circulation. This result suggests the value of the upper-level wind observations from the TCI dropsondes in depicting a more accurate near-storm circulation at upper levels.

The upper-tropospheric inertial stability measures the ability of perturbations to affect the outflow, which has potential influences on hurricane intensity (Rappin et al. 2011). Figure 7 shows the azimuthally averaged inertial stability in the analyses of the experiments BASE and ALLTCI and their differences. The algorithm to calculate inertial stability follows Chen and Zhang (2013), namely, $I^{2}=(f+2 V / r)[f+1 /$ $r \partial(r V) / \partial r]$, where $f, V$, and $r$ are the Coriolis parameter, the tangential wind, and the radius, respectively. It is expected that the lower levels typically have stronger inertial stability than upper levels (Rappin et al. 2011), which is consistent with Figs. 7a and $7 \mathrm{~b}$. Inertial stability in the upper levels of ALLTCI is stronger within the eyewall, but weaker in the outflow region. The former is helpful to the formation and maintenance of the upper-level warm core and eyewall (Vigh and Schubert 2009), and the latter allows stronger radial displacements, which is potentially favorable for stronger outflow (Rappin et al. 2011).

\section{b. Analyses of thermodynamic variables}

Similar to Fig. 6, the analyses of thermodynamic structure, that is, the perturbation temperature $\left(T^{\prime}\right)$ and the relative humidity $(\mathrm{RH})$ in the analyses of the four experiments are shown in Fig. 8. $T^{\prime}$ is calculated by removing the environmental temperature (average over the area of approximately $1000 \mathrm{~km} \times 1000 \mathrm{~km}$ ) at each level. Two maxima in the warm core exist for the four experiments, at about 200 and $600 \mathrm{hPa}$, which is consistent with the structure depicted by the TCI dropsonde observations (see Fig. 18a in Rogers et al. 2017) and also similar to other cases (e.g., Stern and 
(a) Tan \& Rad (BASE)

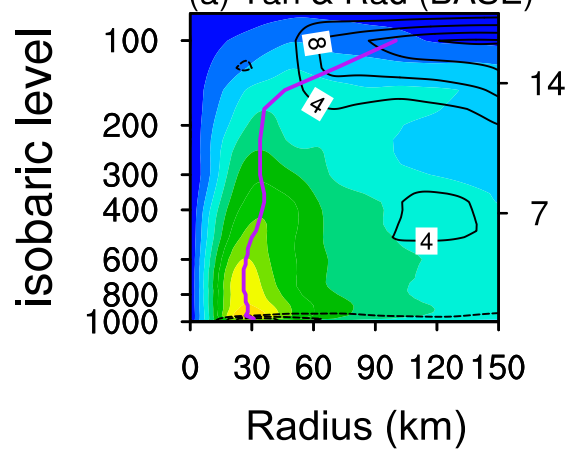

(b) Tan \& Rad (HLTCITQ)

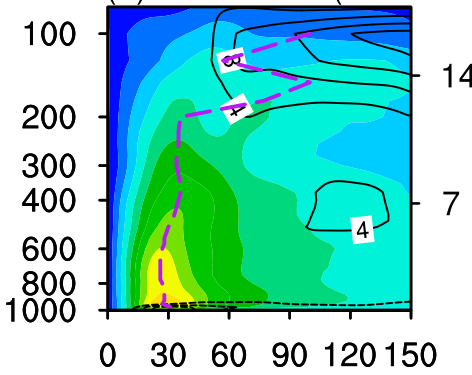

(c) Tan \& Rad (HLTCIUV)

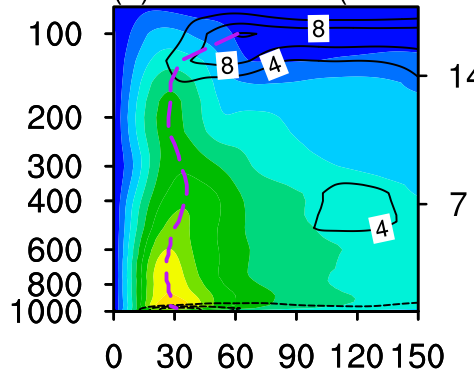

FIG. 6. Initial analyses of the azimuthally averaged tangential $\left(\mathrm{ms}^{-1}\right.$; shaded) and radial ( $\mathrm{m} \mathrm{s}^{-1}$; contour) wind for experiments (a) BASE, (b) HLTCITQ, (c) HLTCIUV, and (d) ALLTCI. (e)-(g) The differences of HLTCITQ, HLTCIUV, and ALLTCI from BASE, respectively. Purple lines are the radius of the maximum wind (RMW), solid for BASE and dashed for the other three experiments.

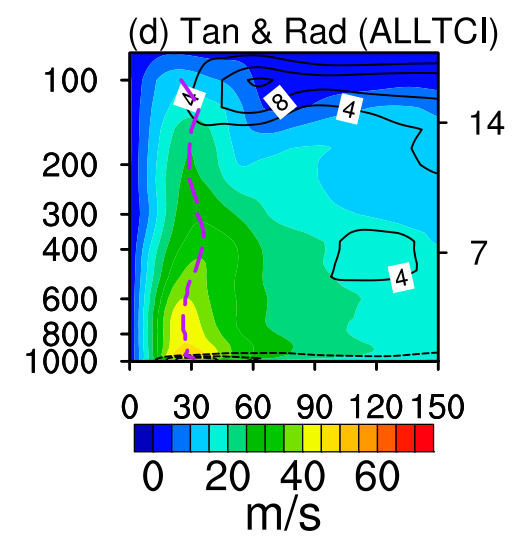

(e) HLTCITQ-BASE
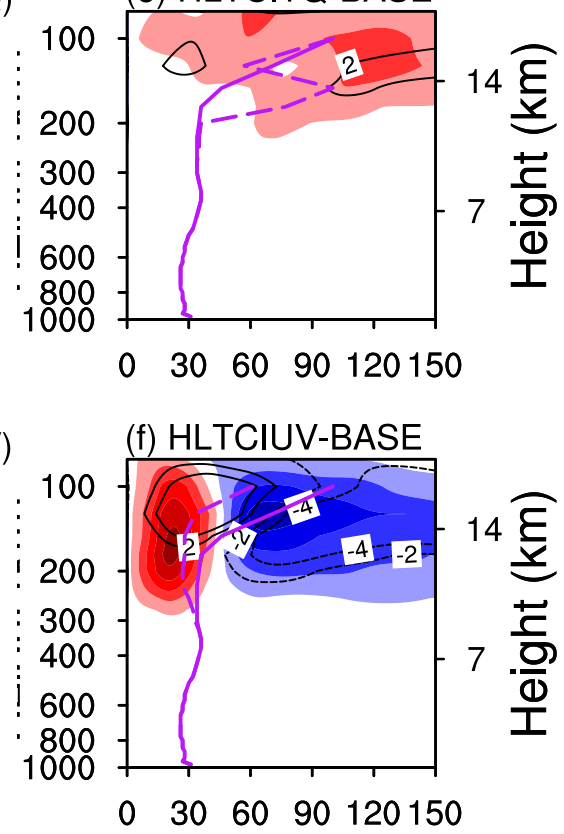

(g) ALLTCI-BASE

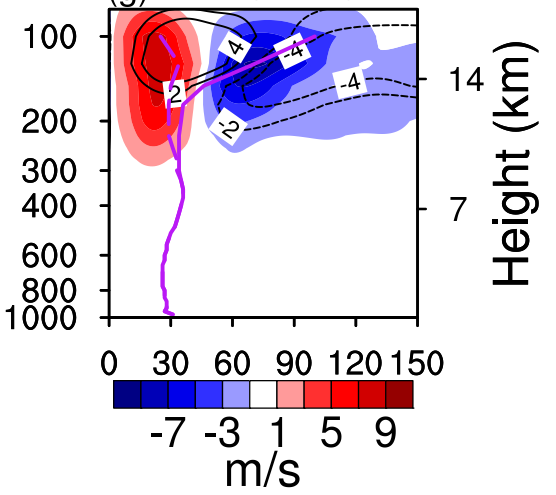

Zhang 2016). By assimilating the upper-level TCI thermodynamic observations, the upper levels out to $150 \mathrm{~km}$ and above $150 \mathrm{hPa}$ overall become warmer and drier, with the maximal increase of temperature (nearly $4.5 \mathrm{~K}$ ) and reduction of RH (around 30\%) located within the warm core at about $100 \mathrm{hPa}$ (see Figs. $8 \mathrm{e}, \mathrm{g}$ ). The assimilation of TCI kinematic observations produces a slightly warmer inner core above $250 \mathrm{hPa}$. The TCI dropsondes provide a direct measure of the thermodynamic structures at upper levels, especially within the TC inner core, which is typically unavailable. While assimilating the upper-level dropsondes changes the thermodynamic structure in the upper levels of the TC and its environment, it remains unclear whether the analyses are actually improved since there are not independent observations available for verification at those upper levels.

\section{Impact of upper-level TCI dropsondes on Patricia structure forecasts}

The structure of the hurricane in the forecasts is analyzed to explore how the differences in analyses lead to different intensity forecasts. Figure 9 shows the azimuthally averaged secondary circulation. At the 20-min lead time, the experiments HLTCIUV and ALLTCI exhibit more upright convection and RMW up to $200 \mathrm{hPa}$ at about $30 \mathrm{~km}$ from the eye center in contrast to BASE and HLTCITQ. This is the response of convection to the more inward-located outflow in the analyses since there is no initial vertical motion in our experiments, just as in the operational HWRF. From 2 to $6 \mathrm{~h}$, the convection in all experiments significantly intensifies, and the eyewall contracts to a radius of nearly $15 \mathrm{~km}$. However, in BASE and HLTCITQ, due to the 

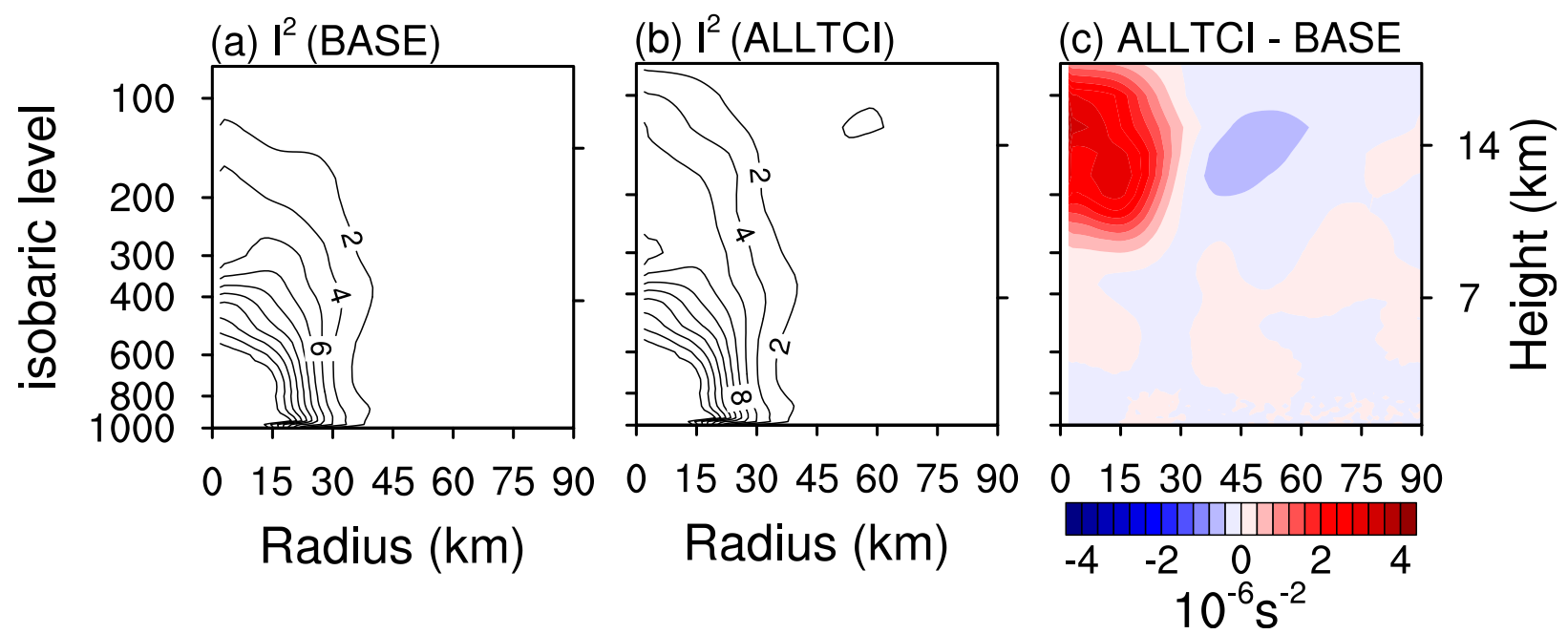

FIG. 7. Initial analyses of the azimuthally averaged inertial stability $\left(\times 10^{-6} \mathrm{~s}^{-2}\right)$ (contour) in the experiments (a) BASE and (b) ALLTCI, and (c) their difference (shaded).

vertical misalignment of outflow and inflow in the analyses, an additional outer band of convection (nearly $20 \mathrm{~km}$ ) develops (see Figs. 9b,c,f,g) and even becomes stronger than the inner band (Fig. 9c). This result can be seen more clearly in the spatial distribution of convection (Figs. 10a,b). As a result, the RMW is located on the inner side of the maximum convection, which is known to be unfavorable for hurricane intensification (Rogers et al. 2013). Until $12 \mathrm{~h}$, as the hurricane further intensifies, the outer convection in BASE and HLTCITQ disappears or merges with the inner band, and all experiments are dominated by a single band of convection in the eyewall (between 15 and $25 \mathrm{~km}$ ) connected with the outflow at an altitude of 100-200 hPa.

Figure 10 illustrates the spatial distribution of vertical velocity at $700 \mathrm{hPa}$ in the 6 -h forecast. In BASE and HLTCITQ there are three apparent concentric convective bands within $50 \mathrm{~km}$ of the center with radii of about 10,20 , and $30 \mathrm{~km}$, respectively, consistent with the azimuthal average plots (Fig. 9). The convective band near the $20-\mathrm{km}$ radius is associated with the outflow near the eyewall in the analysis of BASE, which is outward-shifted relative to ALLTCI (Figs. 6f,g). In contrast, HLTCIUV and ALLTCI have two convective bands within the $50-\mathrm{km}$ radius. Specifically, they both feature a single, isolated convective band within the eyewall between $10-15 \mathrm{~km}$ and an outer band near $30 \mathrm{~km}$. This structure of two convective bands within $50 \mathrm{~km}$ in HLTCIUV and ALLTCI is similar to the WP-3D radar reflectivity in Fig. 12b of Rogers et al. (2017), although the valid time of the forecast is $6 \mathrm{~h}$ later (0000 UTC 23 October vs 1800 UTC 22 October).
The differences between the secondary circulation in BASE and other experiments are further illustrated in Fig. 11. Through all panels, it is consistent that stronger (weaker) outflow corresponds to more (less) intense updraft and inflow. Particularly, the more inward-located outflow in the analyses of HLTCIUV and ALLTCI (see Figs. 6f,g) leads to a strong updraft closer to the eye and a narrower RMW at 6 and $12 \mathrm{~h}$ (see Figs. 11g,h,k,l). HLTCITQ also exhibits stronger eyewall convection and narrower RMW than BASE, although the differences within the first $6 \mathrm{~h}$ (Figs. 11a-c) are smaller than those in HLTCIUV and ALLTCI. The stronger eyewall convection of HLTCITQ is probably the result of its unbalanced warm anomaly in the upperlevel analysis, which at the 20 -min, short lead time (Fig. 11a) presents a tendency to have more upward motion over a broad region $(15-30 \mathrm{~km})$ between 100 and $200 \mathrm{hPa}$.

The narrower RMW and eyewall in HLTCITQ, HLTCIUV, and ALLTCI than in BASE can be seen in Fig. 12 as well, which verifies the surface $(10 \mathrm{~m})$ wind amplitude in 12-h forecasts against the stepped frequency microwave radiometer (SFMR) and the $700-\mathrm{hPa}$ wind amplitude against the flight-level observations, respectively. Although the eyewalls in the four experiments are overall weaker and larger than that observed, ALLTCI still exhibits higher peak wind speed and narrower eyewall than BASE, especially over the southern transect of the flight. HLTCIUV and HLTCITQ have weaker and stronger peak surface winds, respectively, and somewhat narrower eyewall than BASE over the northern transect. Over the southern transect, they perform very similarly to ALLTCI and all three experiments are consistently better than BASE. The 
(a) T' \& RH (BASE)

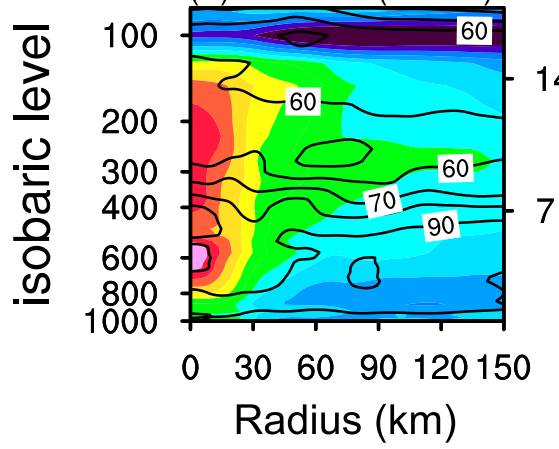

(b) T'\& RH (HLTCITQ)

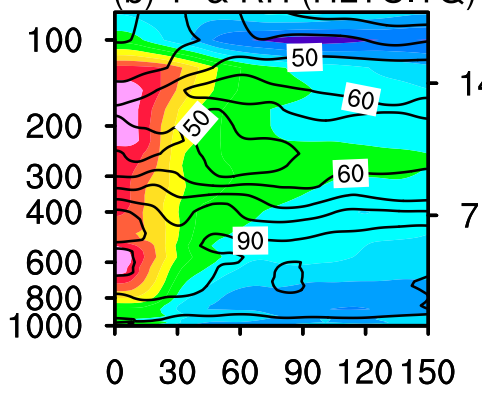

(c) T'\& RH (HLTCIUV)

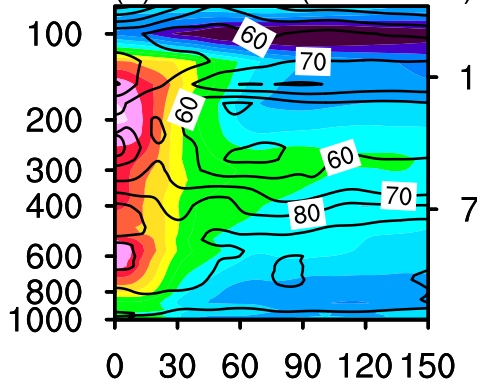

FIG. 8. As in Fig. 6, but for the perturbation temperature ( $T^{\prime}$, unit: $\mathrm{K}$; shaded) and relative humidity ( $\mathrm{RH}, \%$; contour). (d) T' \& RH (ALLTCI)

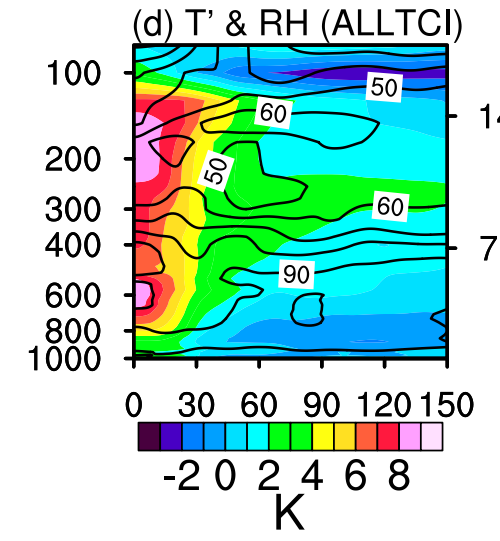

(e) HLTCITQ-BASE
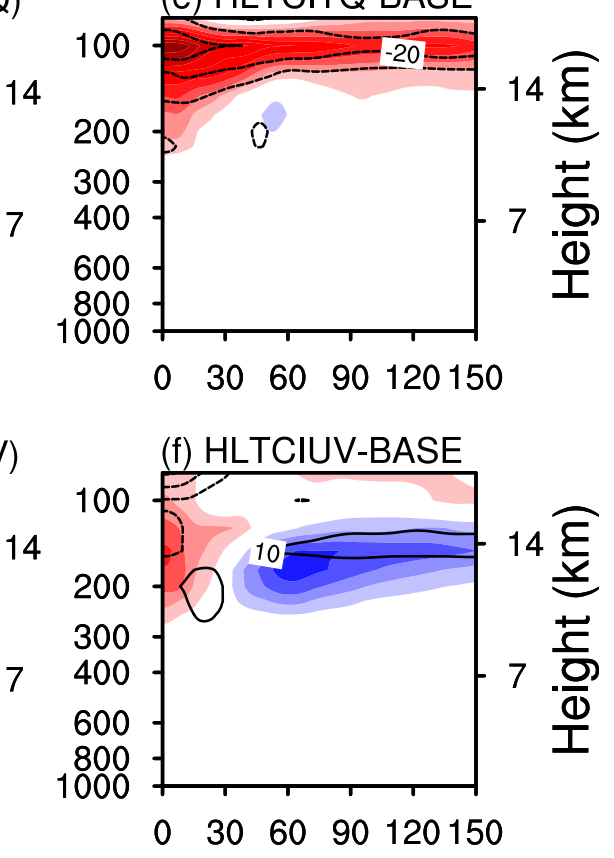

(g) ALLTCI-BASE

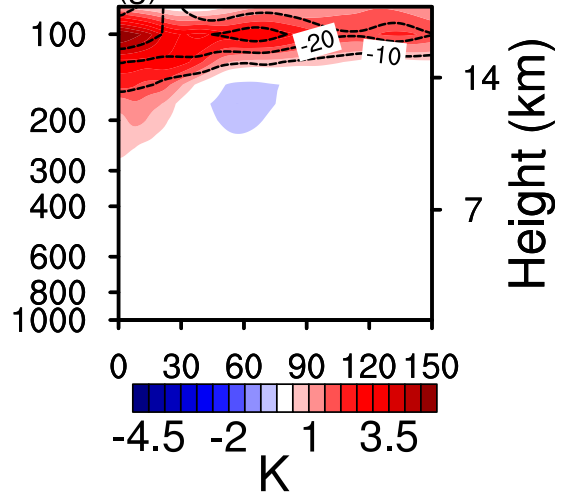

results for the flight-level observations are very similar to those for the SFMR. The verification indicates that the assimilation of the kinematic and thermodynamic observations from the TCI dropsondes, although at upper levels, has positive impacts on the structure and intensity forecasts of lower-level wind near the eyewall. The forecasts of the upper-level wind field at the 12-h lead time are also verified against the AMVs, but the experiments do not present marked differences in terms of the RMS error of wind amplitude. This is probably because the AMVs are mostly distributed over the TC outer environment, while the wind field forecasts differ primarily near the inner-core and eyewall regions.

Latent heat release in the eyewall is well known to significantly impact the evolution of TC intensity through its effect on the development of the warm core (Halverson et al. 2006). Therefore, following the diagnostics on the TC secondary circulation in Figs. 9-11, Fig. 13 shows the azimuthally averaged diabatic heating rate and secondary circulation for all experiments and their differences at the 6 - and 12 -h lead times. The diabatic heating rate is calculated following the approximate algorithm in Wang et al. (2016). It can be seen that the maxima of the diabatic heating rate for the four experiments are all located at the altitude of about $400 \mathrm{hPa}(\sim 7 \mathrm{~km})$ slightly inside the RMW at $6 \mathrm{~h}$ (Figs. 13a-d) and within the RMW at $12 \mathrm{~h}$ (Figs. 13h-k). They primarily differ by their distances to the center of the TC and by their strength. At the 6-h lead time, the diabatic heating rates in BASE and HLTCITQ both have two maximum bands slightly inside and outside 
(a) $20 \mathrm{~min}$ (BASE)

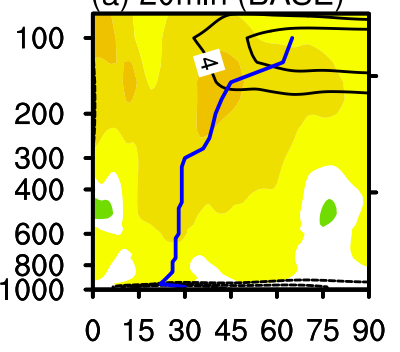

(e) 20min (HLTCITQ)
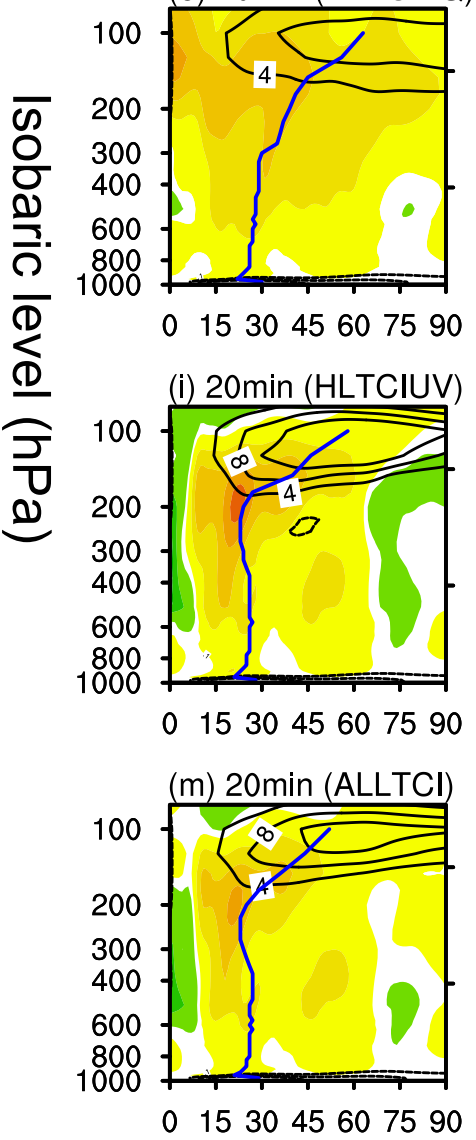

(b) $2 \mathrm{hr}$ (BASE)

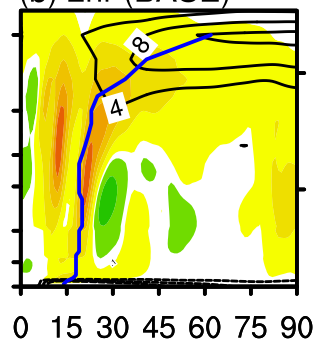

(f) $2 \mathrm{hr}$ (HLTCITQ)

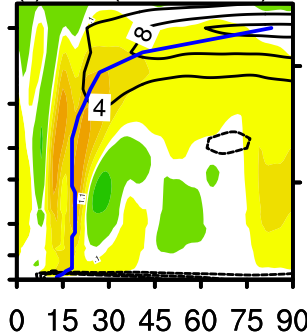

(j) $2 \mathrm{hr}$ (HLTCIUV)

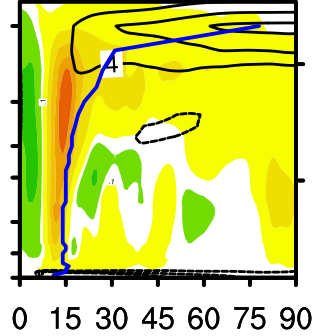

(n) $2 \mathrm{hr}$ (ALLTCl)

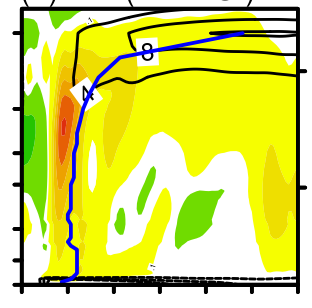

$0 \quad 153045607590$ (c) $6 \mathrm{hr}$ (BASE)

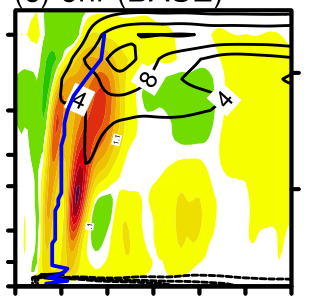

$0 \quad 153045607590$

(g) $6 \mathrm{hr}$ (HLTCITQ)

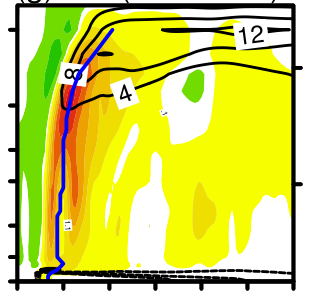

$0 \quad 153045607590$

(k) 6hr (HLTCIUV)

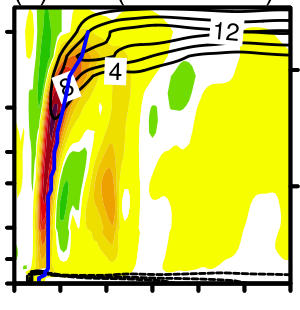

$0 \quad 153045607590$

(o) $6 \mathrm{hr}$ (ALLTCI)

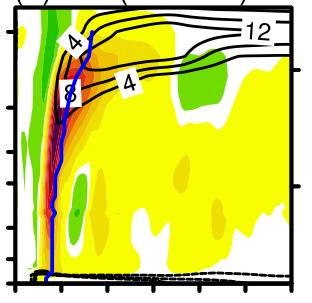

$0 \quad 153045607590$ (d) $12 \mathrm{hr}$ (BASE)

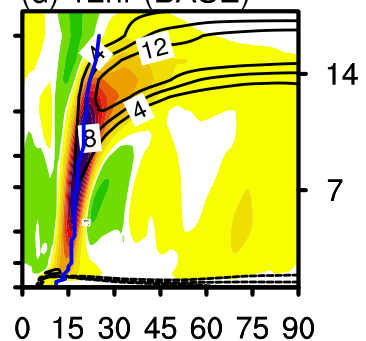

(h) 12hr (HLTCITQ)

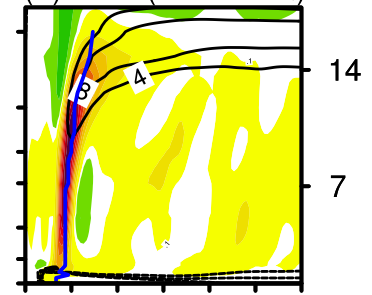

$0 \quad 153045607590$

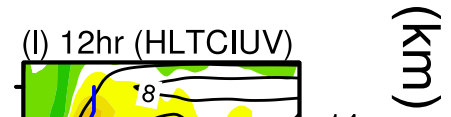

Radius (km)

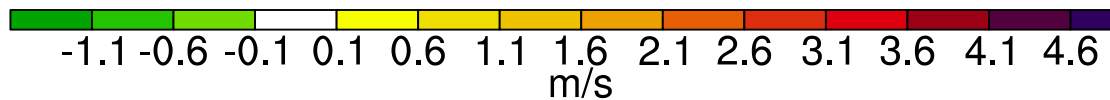

FIG. 9. The azimuthally averaged vertical $\left(\mathrm{m} \mathrm{s}^{-1}\right.$; shaded) and radial ( $\mathrm{m} \mathrm{s}^{-1}$; contour) wind for BASE at lead times (a) $20 \mathrm{~min},(\mathrm{~b}) 2 \mathrm{~h}$, (c) $6 \mathrm{~h}$, and (d) $12 \mathrm{~h}$. The other three rows are same as the first row but for different experiments HLTCITQ, HLTCIUV, and ALLTCI, respectively. Blue lines represent the RMW.

the RMW (at about 10- and 20-km radii), respectively. This distribution is similar to the structure of the two eyewall convective bands (see Figs. 9c,g). In contrast, HLTCIUV and ALLTCI present a unique and stronger diabatic heating band somewhat inside the RMW $(\sim 10 \mathrm{~km}$; cf. Figs. 13c,d, and 13a,b). At $12 \mathrm{~h}$, the eyewall for BASE is farther away from the eye center (cf. Figs. $13 \mathrm{~h}$ and $13 \mathrm{i}-\mathrm{k}$ ) than the other three experiments. Consistently, HLTCITQ, HLTCIUV, and ALLTCI all produce strong diabatic heating closer to the warm core than BASE from low levels to even $100 \mathrm{hPa}$ at 6 and $12 \mathrm{~h}$ (Figs. 13e-g and 131-n), except HLTCITQ at $6 \mathrm{~h}$, which 
(a) w@700hPa (BASE) $\mathrm{m} / \mathrm{s}$

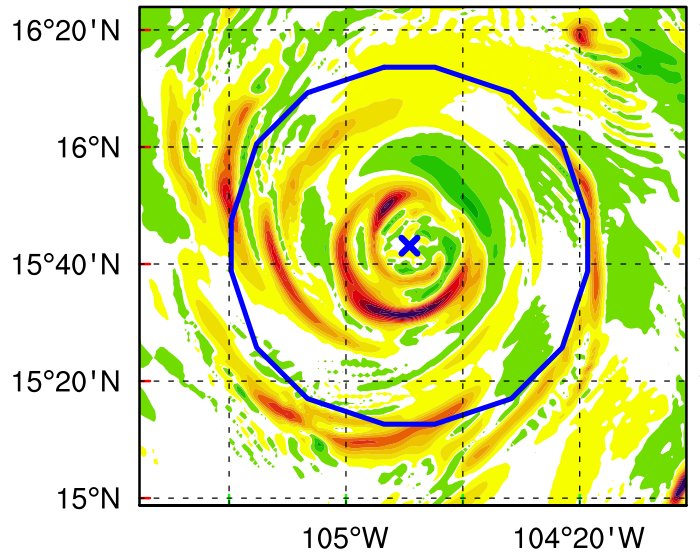

(c) w@700hPa (HLTCIUV) $\mathrm{m} / \mathrm{s}$

$16^{\circ} 20^{\prime} \mathrm{N}$
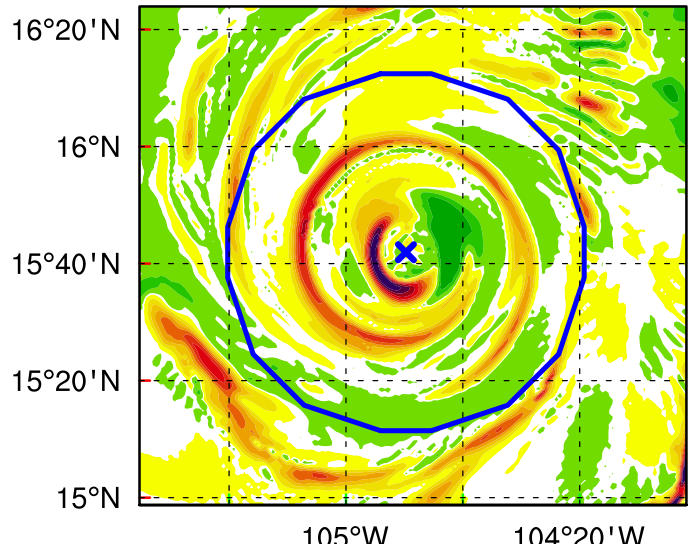

$105^{\circ} \mathrm{W}$

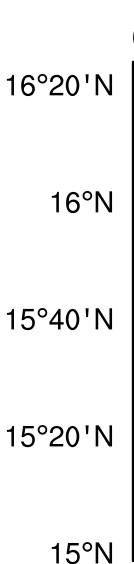

(b) w@700hPa (HLTCITQ)

$\mathrm{m} / \mathrm{s}$

$15^{\circ} \mathrm{N}$

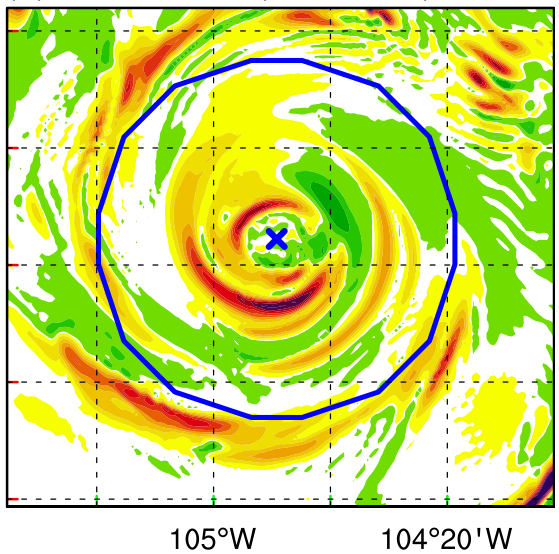

(d) w@700hPa (ALLTCI) $\mathrm{m} / \mathrm{s}$

$16^{\circ} 20^{\prime} \mathrm{N}$

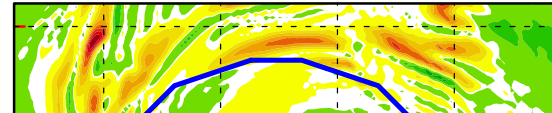

$16^{\circ} \mathrm{N}$

$15^{\circ} 40^{\prime} \mathrm{N}$

$15^{\circ} 20^{\prime} \mathrm{N}$

$15^{\circ} \mathrm{N}$

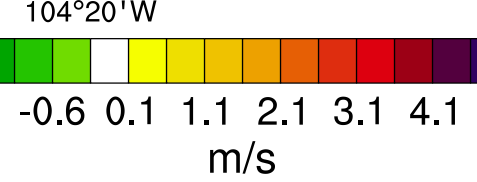

FIG. 10. Spatial distribution of vertical velocity $(w)$ at $700 \mathrm{hPa}$ at the 6-h lead time. Blue cross and circles denote the storm center and radius of $50 \mathrm{~km}$ from the center, respectively.

has a relatively small difference from BASE (Fig. 13e). Overall this result is consistent with the expectation that stronger updrafts correspond to more diabatic heat release.

The diabatic heating in the inner core due to the latent heat release from condensation in the eyewall has a significant contribution to the formation of the warm core (Anthes 1974; Vigh and Schubert 2009). Figure 14 illustrates the azimuthally averaged $T^{\prime}$ and $\mathrm{RH}$ in the forecasts of the experiments and their differences. At the 6-h lead time, the unique maximum $T^{\prime}$ of the warm core is located at about $300 \mathrm{hPa}$ (Figs. 14a-d) and increases in altitude to $200 \mathrm{hPa}$ at $12 \mathrm{~h}$ (Figs. $14 \mathrm{~h}-\mathrm{k}$ ) as Patricia intensifies. As expected, the eye center is very dry relative to the environment (Jordan 1961; Franklin et al. 1988). At $6 \mathrm{~h}$, HLTCIUV and ALLTCI have warmer and moister updrafts slightly inside the RMW $(\sim 10 \mathrm{~km})$ than BASE (Figs. 14f,g) associated with their stronger convection (Figs. 11g,k) and enhanced diabatic heating (Figs. 13f,g) near the similar radius. Such thermodynamic differences of updrafts become much less significant at $12 \mathrm{~h}$ (Figs. 14m,n). Nonetheless, HLTCIUV and ALLTCI both manifest significantly warmer inner cores than BASE at 6 and $12 \mathrm{~h}$, probably related to their stronger diabatic heating within the eyewall. HLTCIUV displays more dramatic inner-core warming and drying than ALLTCI at $6 \mathrm{~h}$, which indicates an intense thermodynamic adjustment of the inner core in response to the change of kinematic field associated with assimilating the wind observations at the upper levels.

It can be noted that ALLTCI and HLTCITQ have similar RH between 200 and $400 \mathrm{hPa}$ and similar $T^{\prime}$ 
(a) HLTCITQ @20min

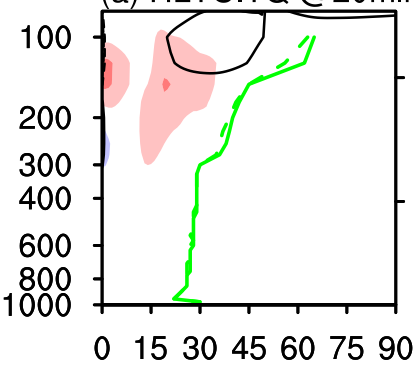

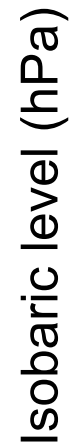

$0 \quad 153045607590$ (b) HLTCITQ @2hr

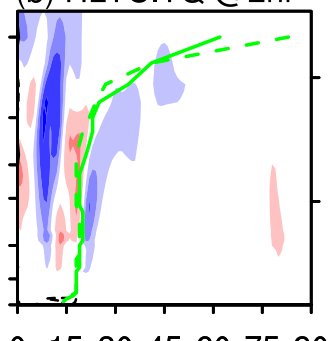

$0 \quad 153045607590$
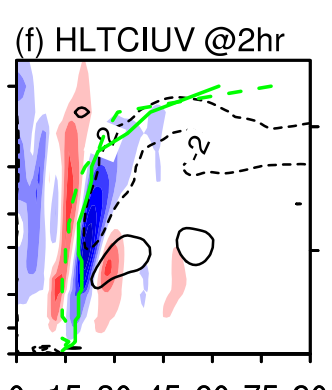

(i) ALLTCI @20min

100
200
300
400
600
800
1000

\section{(j) ALLTCl @2hr}

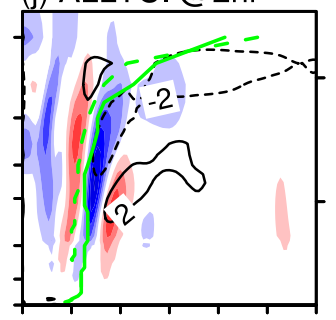

(c) HLTCITQ @6hr

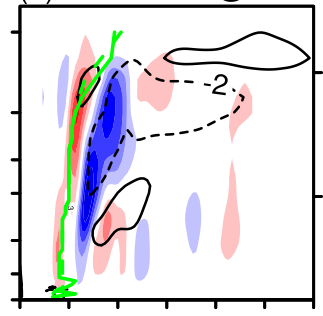

0153045607590

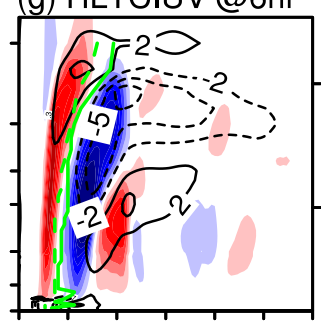

0153045607590

(k) ALLTCI @6hr

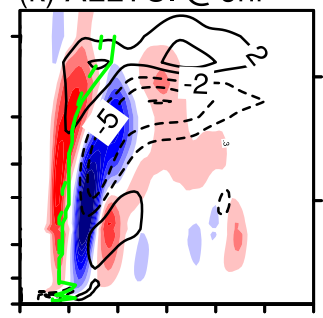

0153045607590

(d) HLTCITQ @12hr

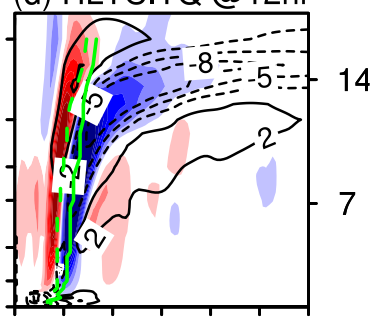

153045607590

\section{(h) HLTCIUV @12hr}

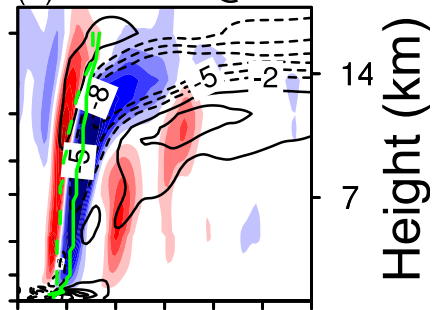

0153045607590

(I) ALLTCI @12hr

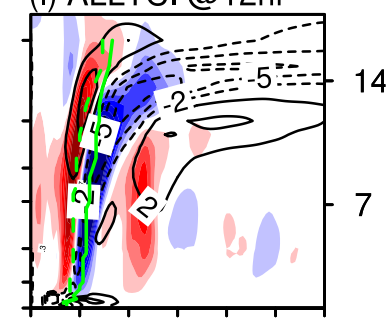

$0 \quad 153045607590$

Radius (km)

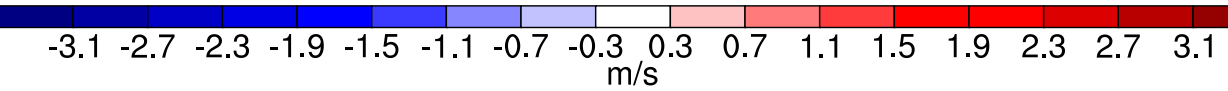

FIG. 11. The forecast differences of the azimuthally averaged vertical ( $\mathrm{m} \mathrm{s}^{-1}$; shaded) and radial ( $\mathrm{m} \mathrm{s}^{-1}$; contour) wind for HLTCITQ and BASE at (a) $20 \mathrm{~min}$, (b) $2 \mathrm{~h}$, (c) $6 \mathrm{~h}$, and (d) $12 \mathrm{~h}$. (e)-(h),(i)-(l) As in (a)-(d), but show the differences of HLTCIUV and ALLTCI from BASE, respectively. Green solid and dashed lines represent the RMW for BASE and other experiments, respectively.

between 300 and $600 \mathrm{hPa}$ within the warm core at $6 \mathrm{~h}$ (cf. Figs. 14e,g). This result suggests the important impact of directly assimilating the upper-level $T$ and $Q$ observations on correcting the inner-core thermodynamic structure. The somewhat warmer and drier inner core below $500 \mathrm{hPa}$ in HLTCITQ at $6 \mathrm{~h}$ is possibly related to its slightly stronger convection and diabatic heating within the eyewall (see Figs. 11c, $13 \mathrm{e})$. Beyond $6 \mathrm{~h}$, the differences of the eyewall convection between HLTCITQ and BASE are further intensified along with the RI of Patricia, resulting in apparently stronger diabatic heating in the eyewall and warming within the eye for HLTCITQ at $12 \mathrm{~h}$. At the region that is $20-35 \mathrm{~km}$ away from the eye, HLTCIUV,
HLTCITQ, and ALLTCI consistently have stronger secondary updrafts and stronger diabatic heating than BASE, raising the temperature and humidity within the upward motion outside the eyewall (cf. Figs. $13,14)$.

\section{Conclusions and discussion}

This study investigates the impact of the upper-level dropsonde kinematic and thermal observations collected during the TCI field campaign on the analyses and prediction of Hurricane Patricia (2015) using an ensemble-variational DA system for the HWRF Model (Wang et al. 2013; Lu et al. 2017a). The TCI 
(a) SFMR

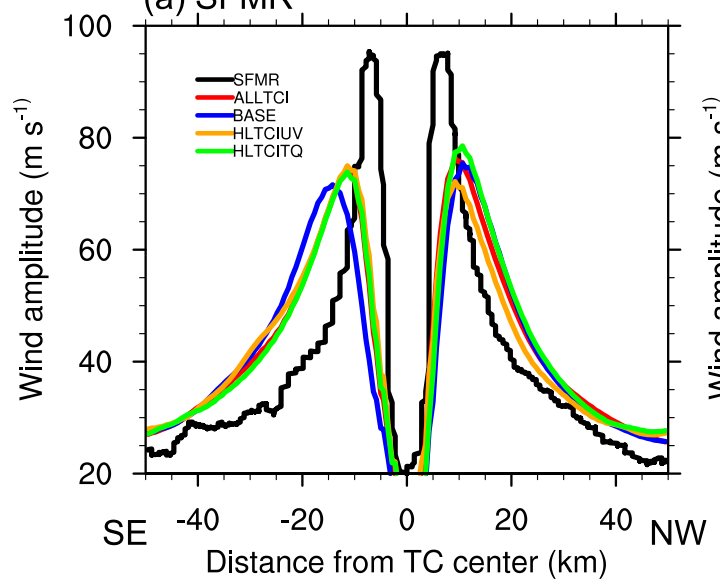

(b) Flight level

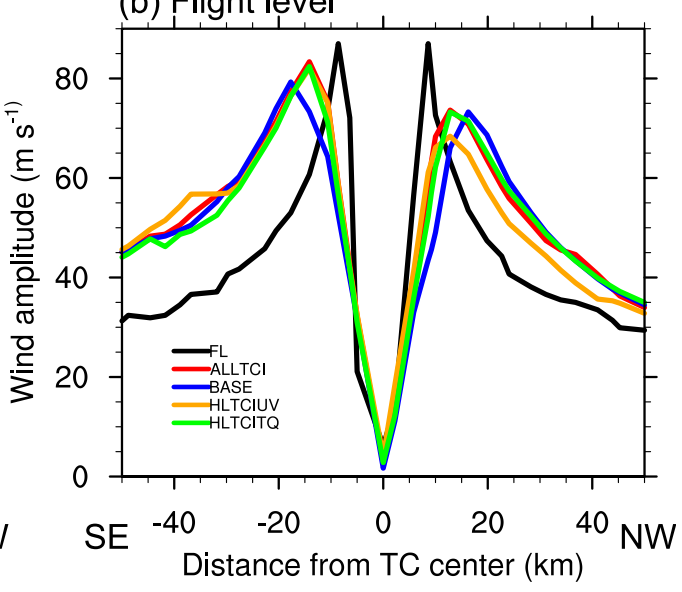

FIG. 12. (a) Surface $(10 \mathrm{~m})$ wind amplitude observed from the stepped frequency microwave radiometer (SFMR, black) on the NOAA WP-3D and the corresponding 12-h forecast of BASE (blue), HLTCITQ (green), HLTCIUV (orange), and ALLTCI (red) valid at 0600 UTC 23 Oct. The SFMR observation is along the flight track from the southeast (SE, negative) to the northwest (NW, positive) at about 0600 UTC 23 Oct. The surface wind forecasts from the four experiments are along the same direction as SFMR but are centered at their own hurricane center position. (b) As in (a), but using the flight-level observations for verification.

dropsonde data can depict the finescale structure of the near-storm outflow and inner core with much higher horizontal resolution than the $\mathrm{GH}$ and traditional dropsondes, providing the prerequisites to address the scientific questions in this study. The case is initialized at 1800 UTC 22 October 2015 during the RI of Patricia. The experiment BASE assimilates all the TCI dropsonde observations except for those at upper levels. The impacts of the upper-level kinematic and thermodynamic observations are explored in separate assimilation experiments to diagnose individual impacts and associated mechanisms.

As a result of the assimilation of these upper-level TCI dropsonde observations, significant impact is found on the analyses of the kinematic and thermodynamic fields in both the inner-core and outflow regions. Assimilating the kinematic observations overall strengthens the tangential and radial wind near the eyewall and weakens the near-storm outflow, producing more accurate upper-level circulation in the analyses (verified against the independent AMV observations). This horizontal alignment of outflow is more favorable for the vertical development of convection and the intensification of the TC. Moreover, such assimilation increases the inertial stability of the upperlevel inner core and decreases it in the outflow region. The assimilation of thermal observations at upper levels results in an overall warmer and drier upper troposphere and lower stratosphere with the maximal impacts located within the warm core at about $100 \mathrm{hPa}$.
In forecasts initialized from each of the different analyses, experiment ALLTCI, which assimilates both the kinematic and thermodynamic observations in upper levels, performs overall the best in predicting the intensity and RI rate. HLTCITQ and HLTCIUV are worse than ALLTCI, but both exceed the performance of BASE. Although the differences of TC intensity forecasts among the experiments are statistically small, the study primarily discusses how the changes in the outflow and warm core due to the assimilation of TCI dropsonde kinematic and thermodynamic observations could lead to or relate to RI.

Diagnostics suggest how the differences of the kinematic and thermodynamic structures between the analyses of BASE and the other three experiments leads to the differences during the subsequent forecasts of intensity and structure of Patricia. The hypothesis drawn from the diagnostics are summarized in Fig. 15. The experiments HLTCIUV and ALLTCI locate the outflow closer to the eyewall than BASE, which therefore leads to more upright convection (or updraft) at the 6- and 12-h forecast lead times. More water vapor is thus lifted and condensed in the eyewall, releasing diabatic heat to warm the inner core and producing a more rapid RI than BASE. Notably, the BASE experiment shows an unrealistic convective band outside the RMW at $6 \mathrm{~h}$, which indicates the importance of assimilating outflow observations in predicting the structure of the secondary circulation and hurricane intensity. Moreover, HLTCIUV has a more dramatic adjustment of the upper-level warm core than 


\section{DH rate \& wvr and Diff @ 6hr}

(a) BASE @6hr

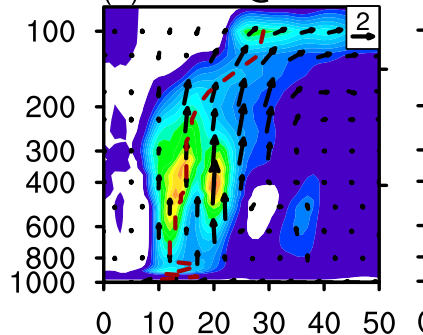

(b) HLTCITQ @6hr

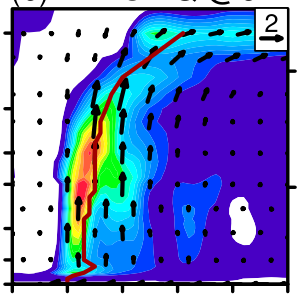

$\begin{array}{llllll}0 & 10 & 20 & 30 & 40 & 50\end{array}$

(e) HLTCITQ @6hr

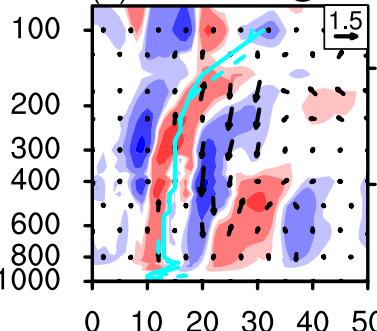

(c) HLTCIUV @6hr

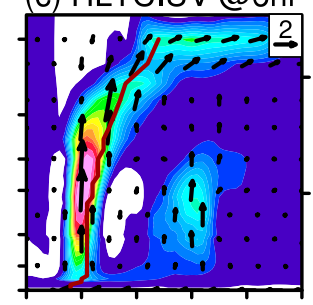

$\begin{array}{llllll}0 & 10 & 20 & 30 & 40 & 50\end{array}$

(f) HLTCIUV @6hr

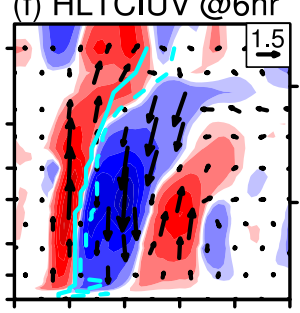

(d) ALLTCI @6hr

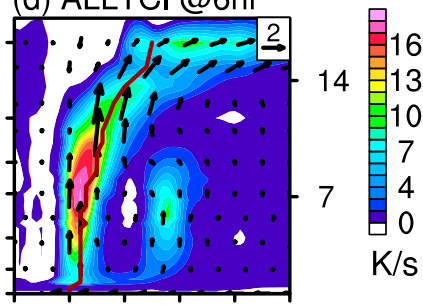

$\begin{array}{llllll}0 & 10 & 20 & 30 & 40 & 50\end{array}$

(g) ALLTCI @6hr

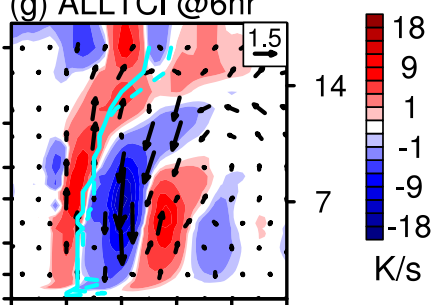



\section{(h) BASE @12hr}

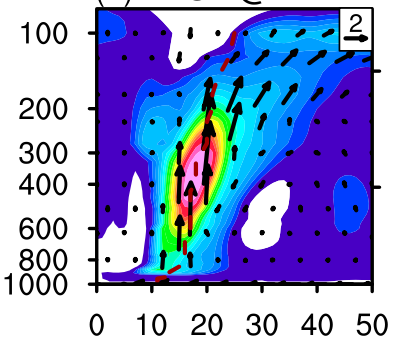

$\begin{array}{llllll}0 & 10 & 20 & 30 & 40 & 50\end{array}$

\section{DH rate \& WV}
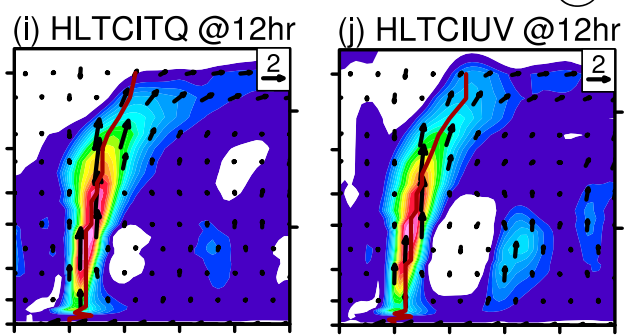

$12 \mathrm{hr}$

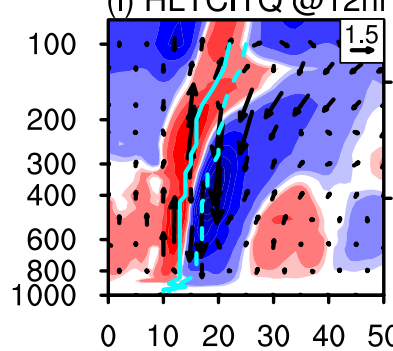

(I) HLTCITQ @12hr
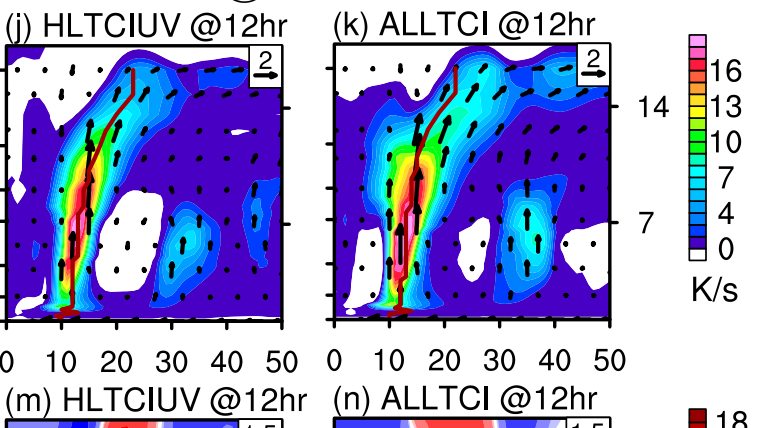

$\begin{array}{llllll}0 & 10 & 20 & 30 & 40 & 50\end{array}$

(n) ALLTCI@12hr

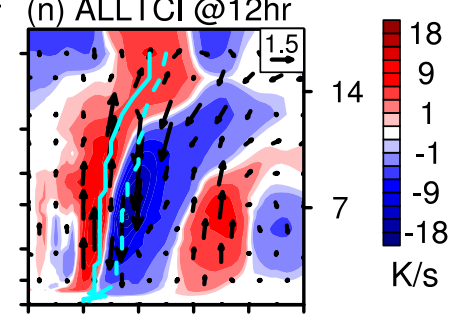

\section{Radius (km)}

FIG. 13. The azimuthally averaged diabatic heating (DH) rate $\left(10^{-3} \mathrm{~K} \mathrm{~s}^{-1}\right.$; shaded) and secondary circulation [vertical ( $\left.w\right)$ and radial $\left(v_{r}\right)$ winds, $\mathrm{m} \mathrm{s}^{-1}$; arrows] at $6 \mathrm{~h}$ for (a) BASE, (b) HLTCITQ, (c) HLTCIUV, and (d) ALLTCI. (e)-(g) The differences of the latter three experiments from BASE are shown, respectively. (h)-(n) As in (a)-(g), but for the results at $12 \mathrm{~h}$. Dashed and solid lines represent the RMW for BASE and other experiments, respectively, dark red for original plots and cyan for difference plots. The radial component of wind vector is scaled by 10 .

ALLTCI at $6 \mathrm{~h}$ since the upper-level thermal observations are not assimilated. In response to the warm and dry corrections made in the upper-level analysis through assimilating only the T and Q observations, HLTCITQ produces stronger intensity forecasts than BASE within the first $18 \mathrm{~h}$.
We conclude that the assimilation of the TCI dropsonde observations at upper levels produces more accurate analyses of TC kinematic and thermodynamic structures in the upper-level near-storm environment and inner-core regions, and therefore improves the predictions of TC intensity and structure. 


\section{T'\& RH and Diff@6hr}

(a) BASE @6hr

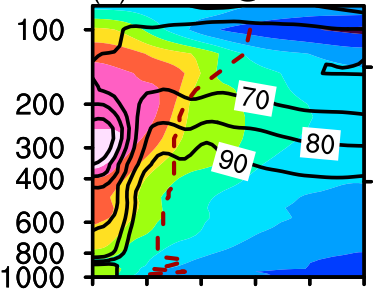

$\begin{array}{llllll}0 & 10 & 20 & 30 & 40 & 50\end{array}$

\section{0}

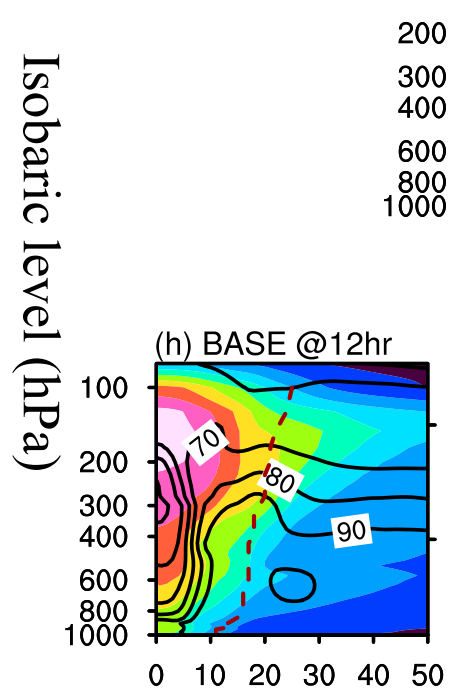

100

200

300

400

600

1000

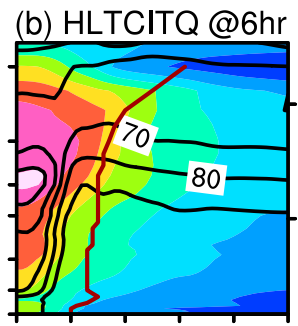

$\begin{array}{llllll}0 & 10 & 20 & 30 & 40 & 50\end{array}$

(e) HLTCITQ @6hr

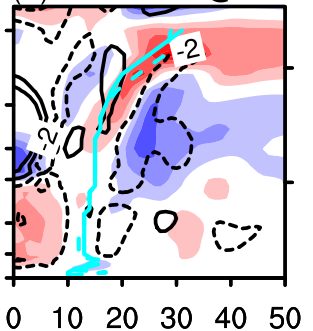

T'\& RH and Diff @12hr
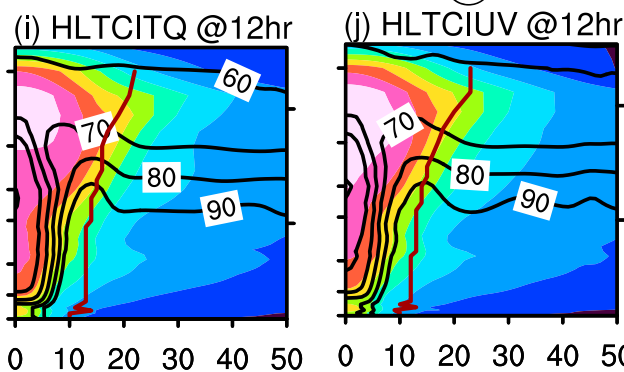

(I) HLTCITQ @12hr

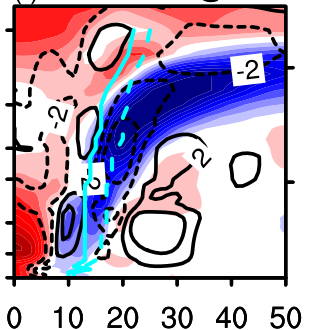

(c) HLTCIUV @6hr

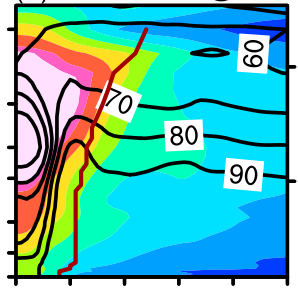

$\begin{array}{llllll}0 & 10 & 20 & 30 & 40 & 50\end{array}$
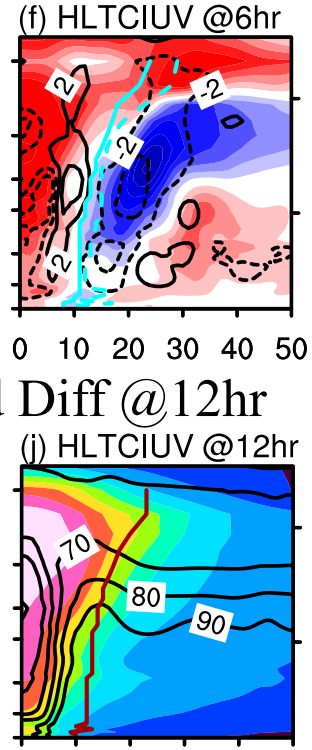

$\begin{array}{llllll}0 & 10 & 20 & 30 & 40 & 50\end{array}$

(m) HLTCIUV @12hı

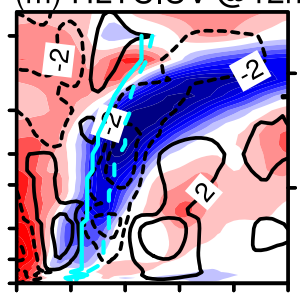

$\begin{array}{llllll}0 & 10 & 20 & 30 & 40 & 50\end{array}$

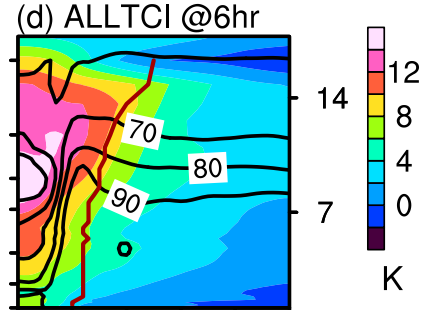

$\begin{array}{llllll}0 & 10 & 20 & 30 & 40 & 50\end{array}$

(g) ALLTCl @6hr
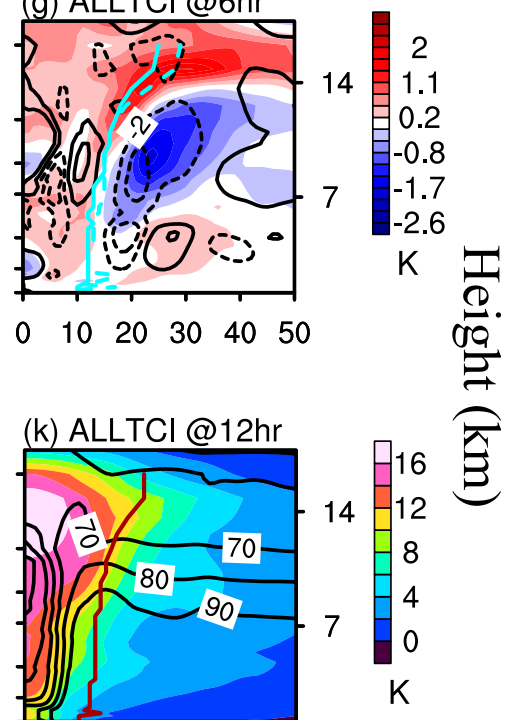

$\begin{array}{llllll}0 & 10 & 20 & 30 & 40 & 50\end{array}$

(n) ALLTCI @12hr

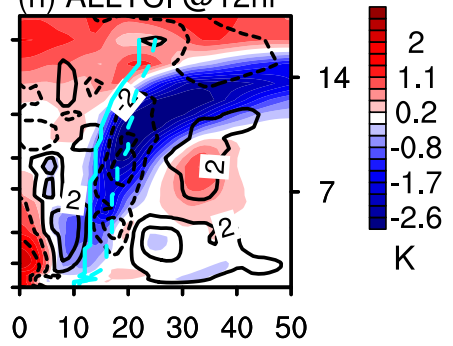

\section{Radius $(\mathrm{km})$}

FIG. 14. As in Fig. 13, but for variables $T^{\prime}$ (K; shaded) and RH (\%; contour).

Our study uses only one case, Patricia (2015), which itself is an extreme case. Moreover, some of the improvements in the analysis and prediction of Patricia demonstrated in this study may not be realized with more standard dropsonde coverage, which is much sparser and samples lower altitude than the TCI dropsondes. Like all other TC case studies, caution should be taken to generalize the results to other cases. Nevertheless, using the data assimilation, the analysis and diagnostics in this study provide a valuable supplement to research of the relationship between a TC's outflow and its intensity and structure evolution. The positive impact of upper-level observations on the TC analysis and prediction revealed in this study, though with a limited number of samples, suggests the need to systematically evaluate the impact of the upperlevel observations for potential future operational reconnaissance aircraft deployment and operational assimilation. 


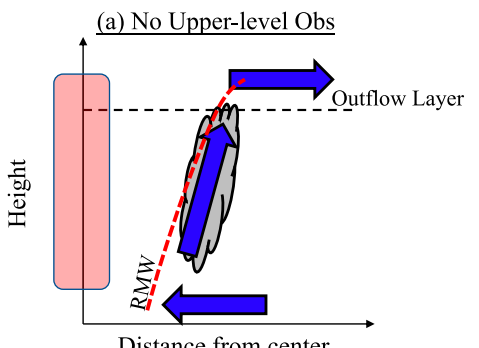

Distance from center

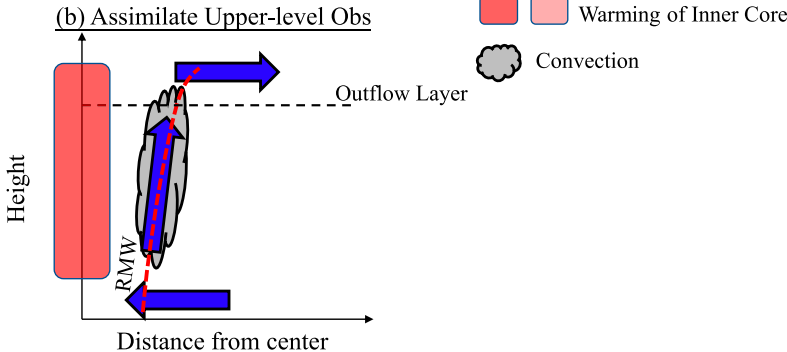

FIG. 15. Schematic of the impacts (a) without and (b) with the assimilation of TCI dropsonde observations in upper levels on the hurricane structure and intensity.

Acknowledgments. The research documented in this paper is supported by ONR Grants N00014-14-1-0125 and N000141712111, and NOAA Grants NA14NWS4680021 and NA16NWS4680028. We greatly appreciate detailed and constructive comments from $\mathrm{Xu} \mathrm{Lu}$, Xinyan Lyu, 2Benjamin Davis, Ben Schenkel, and Nick Gasperoni. We are grateful to TCI PIs James Doyle and Michael Bell for providing TCI dropsonde data and Christopher Velden who provided the CIMSS AMV observations.

\section{REFERENCES}

Aberson, S. D., and J. L. Franklin, 1999: Impact on hurricane track and intensity forecasts of GPS dropwindsonde observations from the first-season flights of the NOAA Gulfstream-IV jet aircraft. Bull. Amer. Meteor. Soc., 80, 421-427, https://doi.org/ 10.1175/1520-0477(1999)080<0421:IOHTAI >2.0.CO;2.

Aksoy, A., S. D. Aberson, T. Vukicevic, K. J. Sellwood, S. Lorsolo, and X. J. Zhang, 2013: Assimilation of high-resolution tropical cyclone observations with an ensemble Kalman filter using NOAA/AOML/HRD's HEDAS: Evaluation of the 2008-11 vortex-scale analyses. Mon. Wea. Rev., 141, 1842-1865, https:// doi.org/10.1175/MWR-D-12-00194.1.

Alpert, J. C., and V. K. Kumar, 2007: Radial wind super-obs from the WSR-88D radars in the NCEP operational assimilation system. Mon. Wea. Rev., 135, 1090-1108, https://doi.org/10.1175/ MWR3324.1.

Anthes, R. A., 1974: The dynamics and energetics of mature tropical cyclones. Rev. Geophys., 12, 495-522, https://doi.org/ 10.1029/RG012i003p00495.

Bell, M. M., and Coauthors, 2016: ONR tropical cyclone intensity 2015 NASA WB-57 HDSS dropsonde data, version 1.0. UCAR/NCAR-Earth Observatory Laboratory, accessed 1 May 2016, https://doi.org/10.5065/D6KW5D8M.
Biswas, M. K., L. Carson, K. Newman, L. Bernardet, E. Kalina, E. Grell, and J. Frimel, 2017: Community HWRF Users's Guide v3.9a. NOAA Tech. Memo. OAR GSD-51, Developmental Testbed Center, 163 pp., https://dtcenter.org/HurrWRF/ users/docs/users_guide/noaa_16281_DS1.pdf.

Black, P. G., L. Harrison, M. Beaubien, R. Bluth, H. Jonsson, A. B. Penny, R. W. Smith, and J. D. Doyle, 2017: High Definition Sounding System (HDSS) for atmospheric profiling. J. Atmos. Oceanic Technol., 34, 777-796, https://doi.org/10.1175/ JTECH-D-14-00210.1.

Braun, S. A., P. A. Newman, and G. M. Heymsfield, 2016: NASA's Hurricane and Severe Storm Sentinel (HS3) investigation. Bull. Amer. Meteor. Soc., 97, 2085-2102, https://doi.org/10.1175/ BAMS-D-15-00186.1.

Burpee, R. W., J. L. Franklin, S. J. Lord, R. E. Tuleya, and S. D. Aberson, 1996: The impact of Omega dropwindsondes on operational hurricane track forecast models. Bull. Amer. Meteor. Soc., 77, 925-933, https://doi.org/10.1175/15200477(1996)077<0925:TIOODO > 2.0.CO;2.

Chen, H., and D. L. Zhang, 2013: On the rapid intensification of Hurricane Wilma (2005). Part II: Convective bursts and the upper-level warm core. J. Atmos. Sci., 70, 146-162, https:// doi.org/10.1175/JAS-D-12-062.1.

Cordoba, M., S. L. Dance, G. A. Kelly, N. K. Nichols, and J. A. Waller, 2017: Diagnosing atmospheric motion vector observation errors for an operational high-resolution data assimilation system. Quart. J. Roy. Meteor. Soc., 143, 333-341, https://doi.org/10.1002/qj.2925.

Doyle, J. D., and Coauthors, 2017: A view of tropical cyclones from above: The Tropical Cyclone Intensity (TCI) experiment. Bull. Amer. Meteor. Soc., 98, 2113-2134, https://doi.org/10.1175/ BAMS-D-16-0055.1.

Ferrier, B. S., 1994: A double-moment multiple-phase fourclass bulk ice scheme. Part I: Description. J. Atmos. Sci., 51, 249-280, https://doi.org/10.1175/1520-0469(1994)051<0249: ADMMPF $>2.0 . \mathrm{CO} ; 2$.

, 2005: An efficient mixed-phase cloud and precipitation scheme for use in operational NWP models. 2005 Spring Meeting, San Francisco, CA, Amer. Geophys. Union, Abstract A42A-02.

Franklin, J. L., S. J. Lord, and F. D. Marks Jr., 1988: Dropwindsonde and radar observations of the eye of Hurricane Gloria (1985). Mon. Wea. Rev., 116, 1237-1244, https://doi.org/10.1175/15200493(1988)116<1237:DAROOT > 2.0.CO;2.

, J. Kaplan, C. S. Velden, and C. M. Hayden, 1990: Some comparisons of VAS and dropwindsonde data over the subtropical Atlantic. Mon. Wea. Rev., 118, 1869-1887, https:// doi.org/10.1175/1520-0493(1990)118<1869:SCOVAD > 2.0.CO;2.

Halverson, J. B., J. Simpson, G. Heymsfield, H. Pierce, T. Hock, and L. Ritchie, 2006: Warm core structure of Hurricane Erin diagnosed from high-altitude dropsondes during CAMEX-4. J. Atmos. Sci., 63, 309-324, https://doi.org/10.1175/JAS3596.1.

Han, J., and H.-L. Pan, 2006: Sensitivity of hurricane intensity forecasts to convective momentum transport parameterization. Mon. Wea. Rev., 134, 664-674, https://doi.org/10.1175/ MWR3090.1.

Hirschberg, P. A., and J. M. Fritsch, 1993: On understanding height tendency. Mon. Wea. Rev., 121, 2646-2661, https://doi.org/ 10.1175/1520-0493(1993)121<2646:OUHT >2.0.CO;2.

Hock, T. F., and J. L. Franklin, 1999: The NCAR GPS dropwind-sonde. Bull. Amer. Meteor. Soc., 80, 407-420, https://doi.org/10.1175/15200477(1999)080<0407:TNGD>2.0.CO;2. 
Holland, G. J., 1997: The maximum potential intensity of tropical cyclones. J. Atmos. Sci., 54, 2519-2541, https://doi.org/10.1175/ 1520-0469(1997)054<2519:TMPIOT>2.0.CO;2.

- , and R. T. Merrill, 1984: On the dynamics of tropical cyclone structure changes. Quart. J. Roy. Meteor. Soc., 110, 723-745, https://doi.org/10.1002/qj.49711046510.

Hong, S.-Y., and H.-L. Pan, 1996: Nonlocal boundary layer vertical diffusion in a medium-range forecast model. Mon. Wea. Rev., 124, 2322-2339, https://doi.org/10.1175/1520-0493(1996) $124<2322$ :NBLVDI $>2.0 . \mathrm{CO} ; 2$.

Hu, M., G. Ge, C. Zhou, D. Stark, H. Shao, K. Newman, J. Beck, and X. Zhang, 2018: GSI user's guide version 3.7. Developmental Testbed Center, 147 pp., https://dtcenter.org/com-GSI/ users/docs/users guide/GSIUserGuide_v3.7.pdf.

Intrieri, J., and Coauthors, 2014: Global Hawk dropsonde observations of the Arctic atmosphere obtained during the Winter Storms and Pacific Atmospheric Rivers (WISPAR) field campaign. Atmos. Meas. Tech., 7, 3917-3926, https://doi.org/ 10.5194/amt-7-3917-2014.

Jordan, C. L., 1961: Marked changes in the characteristics of the eye of intense typhoons between the deepening and filling stages. J. Meteor., 18, 779-789, https://doi.org/10.1175/15200469(1961)018<0779:MCITCO > 2.0.CO;2.

Kimberlain, T. B., E. S. Blake, and J. P. Cangialosi, 2015: National Hurricane Center Tropical Cyclone Report: Hurricane Patricia (20-24 October 2015). National Hurricane Center Tropical Cyclone Rep. EP202015, 32 pp., https://www.nhc.noaa.gov/data/ tcr/EP202015_Patricia.pdf.

Knapp, K. R., M. C. Kruk, D. H. Levinson, H. J. Diamond, and C. J. Neumann, 2010: The International Best Track Archive for Climate Stewardship (IBTrACS): Unifying tropical cyclone data. Bull. Amer. Meteor. Soc., 91, 363-376, https://doi.org/ 10.1175/2009BAMS2755.1.

Komaromi, W. A., and J. D. Doyle, 2017: Tropical cyclone outflow and warm core structure as revealed by HS3 dropsonde data. Mon. Wea. Rev., 145, 1339-1359, https://doi.org/10.1175/ MWR-D-16-0172.1.

Kwon, Y. C., S. Lord, B. Lapenta, V. Tallapragada, Q. Liu, and Z. Zhang, 2010: Sensitivity of air-sea exchange coefficients (Cd and $\mathrm{Ch}$ ) on hurricane intensity. 29th Conf. on Hurricanes and Tropical Meteorology, Tucson, AZ, Amer. Meteor. Soc., 13C.1, https://ams.confex.com/ams/29Hurricanes/techprogram/ paper_167760.htm.

Lacis, A. A., and J. E. Hansen, 1974: A parameterization for the absorption of solar radiation in the earth's atmosphere. J. Atmos. Sci., 31, 118-133, https://doi.org/10.1175/15200469(1974)031<0118:APFTAO > 2.0.CO;2.

Lim, A. H. N., J. A. Jung, S. E. Nebuda, J. M. Daniels, W. Bresky, M. Tong, and V. Tallapragada,, 2019: Tropical cyclone forecasts impact assessment from the assimilation of hourly visible, shortwave, and clear-air water vapor atmospheric motion vectors in HWRF. Wea. Forecasting, 34, 177-198, https:// doi.org/10.1175/WAF-D-18-0072.1.

Lu, X., and X. Wang, 2019a: Improving hurricane analyses and predictions with TCI, IFEX field campaign observations, and CIMSS AMVs using the advanced hybrid data assimilation system for HWRF. Part I: What is missing to capture the rapid intensification of Hurricane Patricia (2015) when HWRF is already initialized with more realistic analysis? Mon. Wea. Rev., 147, 1351-1373, https://doi.org/10.1175/MWR-D-18-0202.1.

, - , Y. Li, M. Tong, and X. Ma, 2017a: GSI-based ensemble-variational hybrid data assimilation for HWRF for hurricane initialization and prediction: Impact of various error covariances for airborne radar observation assimilation. Quart. J. Roy. Meteor. Soc., 143, 223-239, https:// doi.org/10.1002/qj.2914.

,,,---- , and V. Tallapragada, 2017b: GSI-based, continuously cycled, dual-resolution hybrid ensemblevariational data assimilation system for HWRF: System description and experiments with Edouard (2014). Mon. Wea. Rev., 145, 4877-4898, https://doi.org/10.1175/MWRD-17-0068.1.

Majumdar, S. J., M. Brennan, and K. Howard, 2013: The impact of dropwindsonde and supplemental rawinsonde observations on track forecasts for Hurricane Irene. Wea. Forecasting, 28, 1385-1403, https://doi.org/10.1175/WAF-D-13-00018.1.

Merrill, R. T., 1988a: Environmental influences on hurricane intensification. J. Atmos. Sci., 45, 1678-1687, https://doi.org/ 10.1175/1520-0469(1988)045<1678:EIOHI>2.0.CO;2.

- 1988b: Characteristics of upper-tropospheric environmental flow around hurricanes. J. Atmos. Sci., 45, 1665-1677, https:// doi.org/10.1175/1520-0469(1988)045<1665:COTUTE $>$ 2.0.CO;2.

Molinari, J., and D. Vollaro, 1989: External influences on hurricane intensity. Part I: Outflow layer eddy angular momentum fluxes. J. Atmos. Sci., 46, 1093-1105, https://doi.org/10.1175/ 1520-0469(1989)046<1093:EIOHIP > 2.0.CO;2.

Poteat, K. O., 1973: A comparison of satellite-derived, low-level and cirrus-level winds with conventional wind observations. J. Appl. Meteor., 12, 1416-1419, https://doi.org/10.1175/15200450(1973)012<1417:ACOSDL > 2.0.CO;2.

Rappin, E., M. C. Morgan, and G. Tripoli, 2011: The impact of outflow environment on tropical cyclone intensification and structure. J. Atmos. Sci., 68, 177-194, https://doi.org/10.1175/ 2009JAS2970.1.

Rogers, R., P. Reasor, and S. Lorsolo, 2013: Airborne Doppler observations of the inner-core structural differences between intensifying and steady-state tropical cyclones. Mon. Wea. Rev., 141, 2970-2991, https://doi.org/10.1175/MWR-D-1200357.1

- S. Aberson, M. M. Bell, D. J. Cecil, J. D. Doyle, J. Morgerman, L. K. Shay, and C. Velden, 2017: Rewriting the tropical record books: The extraordinary intensification of Hurricane Patricia (2015). Bull. Amer. Meteor. Soc., 98, 20912112, https://doi.org/10.1175/BAMS-D-16-0039.1.

Schwartz, C. S., 2016: Improving large-domain convection-allowing forecasts with high-resolution analyses and ensemble data assimilation. Mon. Wea. Rev., 144, 1777-1803, https://doi.org/ 10.1175/MWR-D-15-0286.1.

Schwarzkopf, M. D., and S. Fels, 1991: The simplified exchange method revisited: An accurate, rapid method for computation of infrared cooling rates and fluxes. J. Geophys. Res., 96, 90759096, https://doi.org/10.1029/89JD01598.

Sears, J., and C. S. Velden, 2012: Validation of satellite-derived atmospheric motion vectors and analyses around tropical disturbances. J. Appl. Meteor. Climatol., 51, 1823-1834, https:// doi.org/10.1175/JAMC-D-12-024.1.

Stern, D. P., and F. Zhang, 2016: The warm-core structure of Hurricane Earl (2010). J. Atmos. Sci., 73, 3305-3328, https:// doi.org/10.1175/JAS-D-15-0328.1.

Tallapragada, V., and Coauthors, 2016: Hurricane Weather Research and Forecasting (HWRF) Model: 2015 scientific documentation. NCAR Tech. Note NCAR/TN-522+STR, 122 pp., https://doi.org/10.5065/D6ZP44B5

Velden, C., and K. Bedka, 2009: Identifying the uncertainty in determining satellite-derived atmospheric motion vector 
height attribution. J. Appl. Meteor. Climatol., 48, 450-463, https://doi.org/10.1175/2008JAMC1957.1.

Vigh, J. L., and W. H. Schubert, 2009: Rapid development of the tropical cyclone warm core. J. Atmos. Sci., 66, 3335-3350, https://doi.org/10.1175/2009JAS3092.1.

Wang, X., 2010: Incorporating ensemble covariance in the Gridpoint Statistical Interpolation (GSI) variational minimization: A mathematical framework. Mon. Wea. Rev., 138, 2990-2995, https://doi.org/10.1175/2010MWR3245.1.

— variational (4DEnsVar) data assimilation: Formulation and single resolution experiments with real data for NCEP Global Forecast System. Mon. Wea. Rev., 142, 3303-3325, https:// doi.org/10.1175/MWR-D-13-00303.1.

_ D. Parrish, D. Kleist, and J. Whitaker, 2013: GSI 3DVar-based ensemble-variational hybrid data assimilation for NCEP Global Forecast System: Single-resolution experiments. Mon. Wea. Rev. 141, 4098-4117, https://doi.org/10.1175/MWR-D-12-00141.1.

Wang, Y. P., X. P. Cui, X. F. Li, W. L. Zhang, and Y. J. Huang, 2016: Kinetic energy budget during the genesis period of Tropical Cyclone Durian (2001) in the South China Sea. Mon. Wea. Rev., 144, 2831-2854, https://doi.org/10.1175/MWR-D-15-0042.1.

Wu, T.-C., C. S. Velden, S. J. Majumdar, H. Liu, and J. L. Andersson, 2015: Understanding the influence of assimilating subsets of enhanced atmospheric motion vectors on numerical analyses and forecasts of tropical cyclone track and intensity with an ensemble Kalman filter. Mon. Wea. Rev., 143, 25062531, https://doi.org/10.1175/MWR-D-14-00220.1.
Zhang, B. L., R. S. Lindzen, V. Tallapragada, F. Weng, Q. Liu, J. A. Sippel, Z. Ma, and M. A. Bender, 2016: Increasing vertical resolution in US models to improve track forecasts of Hurricane Joaquin with HWRF as an example. Proc. Natl. Acad. Sci. USA, 113, 11 765-11769, https://doi.org/10.1073/ pnas. 1613800113 .

Zhang, D. L., and H. Chen, 2012: Importance of the upper-level warm core in the rapid intensification of a tropical cyclone. Geophys. Res. Lett., 39, L02806, https://doi.org/10.1029/ 2011 GL050578.

Zhang, F., Y. Weng, J. F. Gamache, and F. D. Marks, 2011: Performance of convection-permitting hurricane initialization and prediction during 2008-2010 with ensemble data assimilation of inner-core airborne Doppler radar observations. Geophys. Res. Lett., 38, L15810, https://doi.org/10.1029/ 2011 GL048469.

Zhang, J. A., F. D. Marks, J. A. Sippel, R. F. Rogers, X. Zhang, S. G. Gopalakrishnan, Z. Zhang, and V. Tallapragada, 2018: Evaluating the impact of improvement in the horizontal diffusion parameterization on hurricane prediction in the operational Hurricane Weather Research and Forecasting (HWRF) Model. Wea. Forecasting, 33, 317-329, https://doi.org/10.1175/ WAF-D-17-0097.1.

Zhu, P., B. Tyner, J. A. Zhang, E. Aligo, S. Gopalakrishnan, F. D. Marks, A. Mehra, and V. Tallapragada, 2018: Role of eyewall and rainband eddy forcing in tropical cyclone intensification. Atmos. Chem. Phys. Discuss., https://doi.org/10.5194/ acp-2018-610, in press. 